\title{
OPHTHALMIC HERPES ZOSTER
}

\author{
RONALD J. MARSH and MATTHEW COOPER \\ London
}

\begin{abstract}
SUMMARY
A current review of ophthalmic zoster is presented including its virology, immunology, epidemiology and pathogenesis. We give our findings in 1356 patients referred to the Zoster Clinic at Moorfields Eye Hospital, London. The treatment of the disease and its ocular complications is discussed.
\end{abstract}

Ophthalmic herpes zoster is a disease varying in severity from devastating, threatening life and sight, to so mild that it may pass unnoticed. The ophthalmic division of the fifth cranial nerve is affected in $7-17.5 \%$ of herpes zoster patients. ${ }^{1-5}$ Ocular involvement complicates approximately $50 \%$ of these cases and very rarely cases of maxillary herpes zoster, ${ }^{1}$ affecting many of the tissues of the globe and orbit by highly varied types of lesions.

We felt it would be helpful to report our experience with the disease because the large number of cases we have seen has led us to form slightly different ideas from many previous publications as to the nature of the disease, its complications and management. We gained our experience in the Zoster Clinic which was started at Moorfields Eye Hospital, London, in 1967 by Professor Barrie Jones as part of the External Disease Clinic. Since then the clinic has expanded and chiefly sees patients referred from Casualty. These patients come mainly from the Greater London area and are referred rapidly by their general practitioners after onset of the disease. A relatively small number of patients was referred for second opinion. Since 1971 one of the authors has supervised the clinic continuously. From 1972 to 1988 all new patients were entered into a specially designed database which was continuously upgraded. All those with inadequate details or follow-up of less than a year were removed from the database, leaving 1356 patients. The vast majority of patients received no systemic antiviral or steroid therapy before they saw us and were physically well before the disease started. The figures given throughout this paper on complication incidence are based on this database. However, the series as a whole was slightly biased because those patients with insufficient follow-up were excluded and most of them tended to have very mild zoster.

Correspondence to: R. J. Marsh, MB.BS, FRCS, Department of Clinical Ophthalmology, Moorfields Eye Hospital, City Road, London EC1V 2PD, UK.
Fig. 1 shows the age and sex distribution, which is biased in favour of females and compares with $50.7 \%$ males, $49.3 \%$ females in another series. ${ }^{5}$ The 1981 census for Greater London recorded $48 \%$ males and $52 \%$ females.

\section{ONSET}

There is a prodromal influenza-like illness of varying duration, with headache, pyrexia, malaise, depression, and sometimes neck stiffness, which may last up to a week before the rash appears. This is shortly followed by localised pain over the distribution of the ophthalmic nerve, lymph node swelling in the corresponding drainage areas and, occasionally, a red eye. The localised pain is well known to precede the rash by several days in some cases. This probably represents the replication and migration phase of the disease and is possibly accompanied by a limited viraemia.

\section{RASH}

The rash varies enormously in distribution, density and severity. It commences as macules which rapidly progress to papules, vesicles and pustules. Crusts start to form from about 6 days onwards. All, or just one, of the cutaneous branches of the ophthalmic nerve are affected. The lesions vary from small, discrete, scattered and superficial to large, confluent and deep with haemorrhagic bullae. The latter are probably due to a vasculitis in the dermal papillae leading to severe tissue ischaemia. In our patients the rash was mild in 430, moderate in 743 and severe in 131 . The average ages for the different degrees of severity of rash were: 64 years for severe, 61 years for moderate and 56 years for mild.

Oedema is a variable complication, tending to develop after the first 2 or 3 days. It may be so pronounced as to completely close the lids of the affected eye and spread across the midline to involve the other lids (giving the erroneous impression that it is a bilateral disease). Furthermore, oedema is not due to secondary infection in the majority of cases, since it rapidly resolves without any antibiotic therapy.

\section{Differential Diagnosis}

The rash can be mimicked by zosteriform herpes simplex 


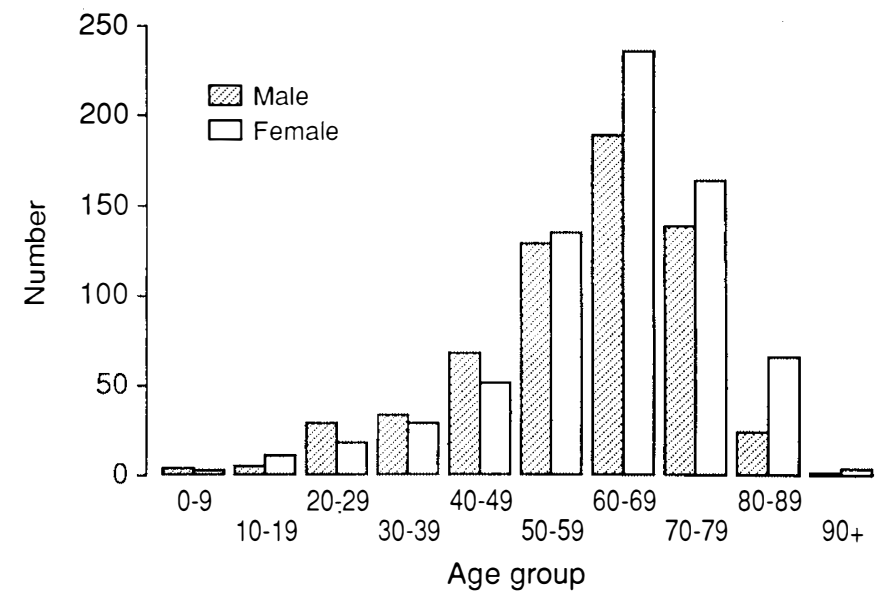

Fig. 1. Age and sex distribution of ophthalmic zoster patients.

which takes on a dermatome distribution. ${ }^{6}$ Herpes simplex vesicles are smaller and frequently recurrent; they do not form the large distinct crusts or the typical punched-out scarring of herpes zoster and are not as painful. The two infections may be differentiated by culturing vesicle fluid and assessing fluorescent antibody membrane antigen (FAMA). ${ }^{7}$ Differentiation from impetigo is usually straightforward because of the lack of dermatome distribution. Very occasionally a brief and mild zosteriform rash appears after trauma to the forehead or eye. It clears in days with no lasting complications. We have no viral cultures on these cases but wonder whether they are caused by a closely related or attenuated strain of varicella/zoster.

\section{SYSTEMIC INVOLVEMENT}

Fortunately the vast majority of patients seen by ophthalmologists are otherwise healthy, except for those in centres specialising in tumours and immunosuppression; only 12 in a continuous series of a 1000 of our cases had malignant disease. ${ }^{8}$

A small number of patients attending eye clinics develop a systemic vesicular rash and severe illness 1-2 weeks after the disease onset. Most of these patients turn out to have reticuloses, other malignant tumours, ${ }^{9}$ diseases causing immunosuppression such as AIDS, or are iatrogenically immunosuppressed (symptomatic zoster). Furthermore herpes zoster is more frequent and severe in patients with these diseases. It is interesting that viruses in the same family as varicella/zoster, the so-called latent viruses (herpes simplex virus, cytomegalovirus and Epstein-Barr) produce severe infections under the same circumstances ${ }^{10}$ Recently an increased incidence of ophthalmic zoster has been described in pre-AIDS patients in New York and Africa. ${ }^{11,12}$

All patients with a systemic rash should therefore be screened by a clinical immunologist or oncologist for malignant disease and immunosuppression. We do not consider it necessary to investigate uncomplicated cases of ophthalmic zoster. ${ }^{8,13}$ There has been a tradition, largely unsubstantiated, that all young children with zoster should be investigated for systemic disease. ${ }^{14}$ Our series included 17 patients under 16 years old none of whom suffered from or developed serious systemic illness. On the other hand, if a child is from a community in which AIDS is endemic we would agree that screening should be done.

\section{OCULAR INVOLVEMENT}

Ocular complications can be categorised primarily into those associated with inflammatory changes, those resulting from nerve damage, and those secondary to tissue scarring. Inflammatory changes may be in the form of dendritic, nummular and disciform keratitis or as a vasculitis in episcleritis/scleritis, iritis, ischaemic papillitis and orbital vasculitis. Changes resulting from nerve damage include neuroparalytic keratitis, some ocular motor palsies and neuralgia. Changes subsequent to tissue scarring are lid deformities, neuralgia and lipid keratopathy.

The course of the ocular disease falls into three phases: acute, chronic and relapsing. Acute lesions of the globe and orbit develop within 3 weeks of the rash. They may resolve rapidly and completely but can lead to a chronic course, especially if untreated, and may linger for years. Alternatively acute lesions may appear to clear but then relapse years after the disease onset - often on suddenly stopping or reducing the topical steroid treatment. Recurrence is a particularly distinctive feature of the disease. Adequate treatment delivered at the start of the acute phase can significantly reduce severe late and chronic complications.

The old rule that cutaneous involvement of the nasociliary nerve heralds ocular complications is a good one (chisquared $p<0.01$ ) but not infallible. We found 6 of our 604 patients with nasociliary nerve involvement had no ocular involvement at all. Vesicles appearing on the lid margins are almost invariably associated with ocular involvement (chi-squared $p<0.01$ ), although it must be emphasised that severe ocular complications may occur with a very mild insignificant rash anywhere on the forehead.

\section{Acute Lesions}

\section{Eyelids}

The lid margin was involved by the rash in 926 cases. Ptosis is common and is usually due to mechanical factors such as inflammation and oedema. Less frequently it is neurological. Haemorrhagic bullae here are a bad sign, heralding severe scarring and all its consequences and post-herpetic neuralgia.

\section{Conjunctivae}

Catarrhal conjunctivitis is one of the commonest manifestations of herpes zoster, occurring in 1015 patients, and is nearly always associated with vesicles on the lid margin. It is generally transitory, resolving within a week, and rarely becomes chronic.

\section{Episclera and sclera}

Episcleritis and scleritis are common complications, occurring mildly in 545 and moderately in 208 patients (Fig. 2). Sectoral or diffuse episcleritis usually appears at 


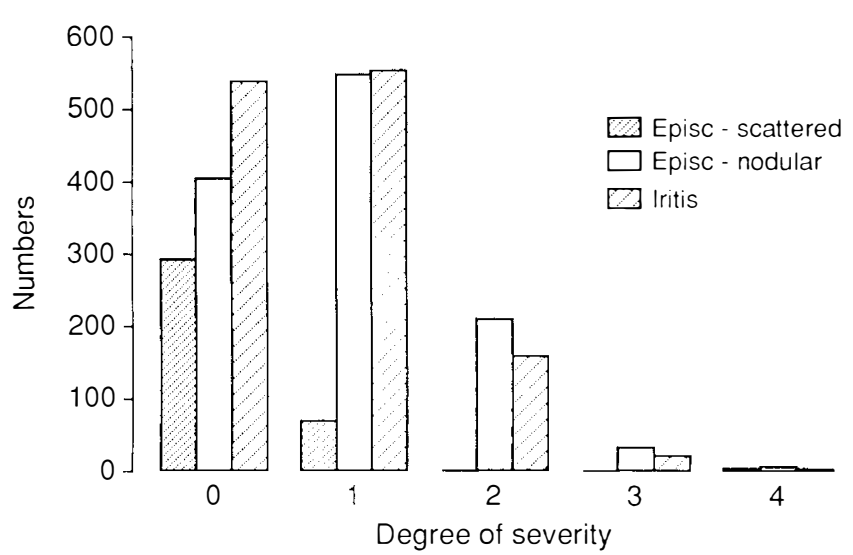

Fig. 2. Numbers of patients with uveoscleral inflammation and its degree of severity.

the onset of the rash when it is frequently concealed by an overlying conjunctivitis. Less commonly, in 37 of our patients, scleritis appeared, usually at the end of the first week. It may be adjacent to the limbus with accompanying corneal stromal infiltrate and swelling, producing sclerokeratitis in $6 \%$ of cases. ${ }^{15}$ Nodular episcleritis occurred in 70 of our patients, usually starting in the second week of the disease. Fluorescein angiography in these cases demonstrates ischaemia in the centre surrounded by dilated leaking episcleral vessels ${ }^{16}$ (Fig. 3a,b) suggesting a vasculitis, but it may be just a lymphocytic response. We have found that mild episcleritis does not require treatment and will slowly resolve without problems.

\section{Cornea (Fig. 4)}

Acute epithelial keratitis may occur concurrently with acute conjunctivitis. This is characterised by small, fine, multiple dendritic or stellate lesions which were observed in 253 cases, although the real figure is probably much higher than this because of the difficulty of corneal examination when the patient has swollen lids and the transitory nature of the lesions. On slit lamp examination they appear slightly raised and are intra-epithelial. They are located generally in the peripheral part of the cornea and occasionally small plaques of opaque desquamated epithelium and mucus overlie them (Fig. 5a). These epithelial lesions stain moderately well with Rose Bengal and fluorescein but only minimally with Alcian blue. They are self-limiting, appearing within a few days of the onset of the rash and resolving 4-6 days later, and are always associated with catarrhal conjunctivitis. They may be followed by an underlying superficial stromal infiltrate. Varicella/ zoster virus has been cultured from them. ${ }^{17}$ Less often a filamentary keratitis occurs which usually lasts only a few days. All these changes may be concealed by lid oedema that prevents proper examination of the cornea during the early period.

Nummular keratitis is the commonest corneal lesion and was seen in 294 patients in the first month and in 411 after 3 months; 152 patients had combined late and early nummular keratitis. It is characterised by multiple, fine granular deposits in the stroma just beneath Bowman's membrane which are surrounded by haloes of stromal haze (Fig. 5b). These appear 10 days or so after the onset of the disease and are at first white but later become brown. Sometimes they underlie preceding epithelial lesions, but more often they are seen in close proximity to thickened corneal nerves. ${ }^{10}$ The haloes surrounding them vary in size and density, are often very sensitive to topical steroid, but have a strong propensity to become chronic or to relapse. In this they resemble the lesions in adenovirus keratitis. Some patients in whom they fail to clear suffer progressive lipid deposition with facetting, all of which may considerably embarrass vision.

Disciform keratitis developed within 1 month in 61 cases and was seen after 3 months in 51 . Early cases present 3-4 weeks after the disease onset. Disciform keratitis is generally situated centrally, but can be eccentric and varies in the degree of stromal oedema and infiltrate (Fig. $3 c$ ). It seems to be based on preceding nummular keratitis with new infiltrate appearing in the stroma underlying the corneal granules, and occasionally is surrounded by infiltrate in the shape of one or several immune rings. Commonly there is an associated iritis with fine keratitic precipitates underlying the swollen stroma. When the disciform keratitis is eccentric it often merges into a sclerokeratitis. When the endothelium is examined with the specular microscope it shows spotty loss of endothelial cells and blebs (Fig. 3d). ${ }^{18,19}$ This form of keratitis can be associated with hypertensive iritis and is often followed much later by a mucous plaque keratitis. It tends to become chronic if untreated but rapidly responds to topical steroid, particularly if this is given early on.

Diffuse corneal oedema developed as the presenting feature in 72 of our patients. It would appear to be due to diffuse damage to the endothelium because later, after the oedema has resolved, endothelial microscopy shows more severe changes than the above. ${ }^{18,19}$ Very fine deposits may be visible with the slit lamp on the endothelial surface and there is often raised intraocular pressure with the minimum of signs of iritis. It is equally sensitive to topical steroid, especially early on.

Neurotrophic keratitis. Total loss of corneal sensation occurred at the onset of the disease in 89 patients, $33 \%$ of whom developed immediate neuroparalytic keratitis with corneal ulceration; there is usually an accompanying severe rash (chi-squared $p<0.01$ ). Neurotrophic keratitis is characterised by generalised corneal epithelial bedewing and punctate epithelial erosions with or without frank interpalpebral epithelial ulceration (Fig. 5c). The epithelium stains moderately well in a punctate fashion with fluorescein and Rose Bengal. It is interesting that in all cases not only is there loss of all corneal sensation but also anaesthesia of the bulbar conjunctiva and lid margins. The ulcers tend to be oval in shape with opaque waterlogged edges and the base stains brilliantly with fluorescein and moderately well with Rose Bengal. The keratitis may be of acute or late onset. Acute cases occur as early as 10 days and those of late onset 2 years and more after the first signs of cutaneous zoster. Viscous drops and pro- 


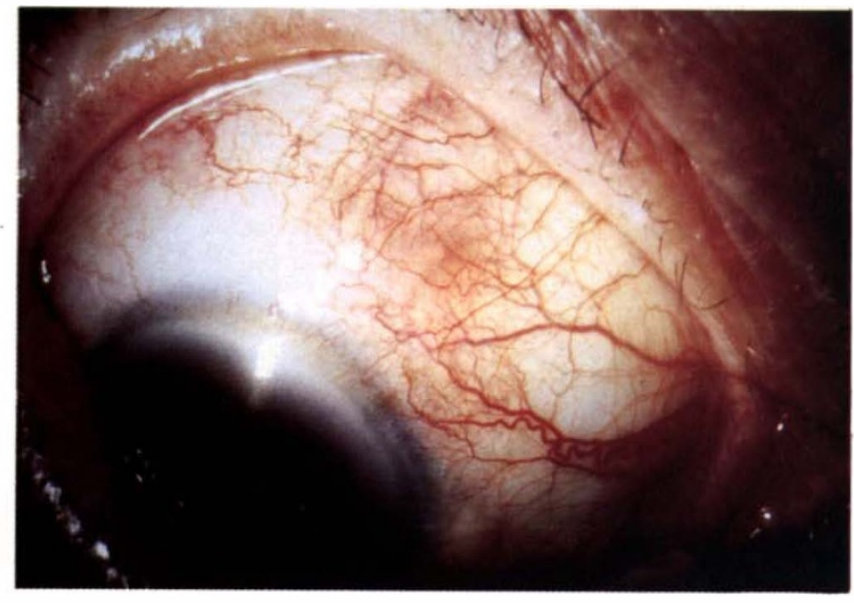

(a)

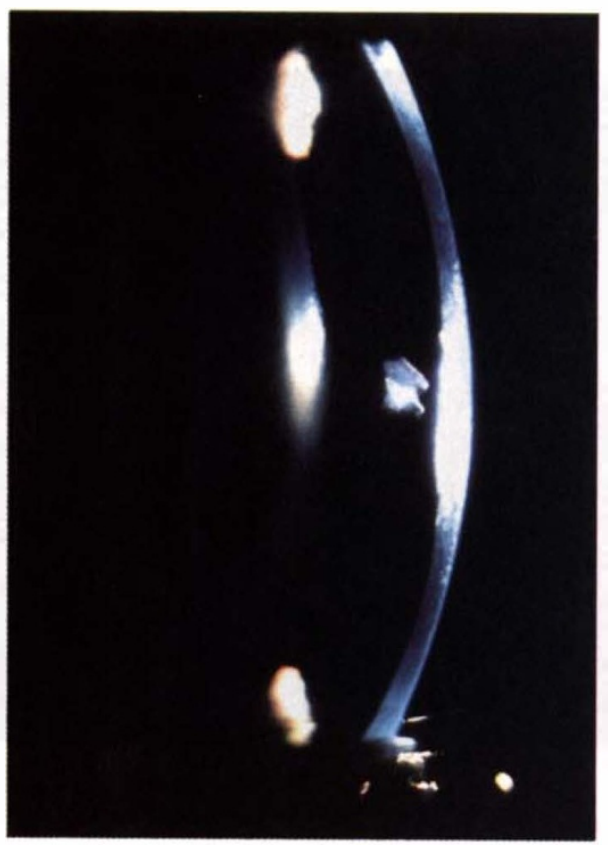

(c)

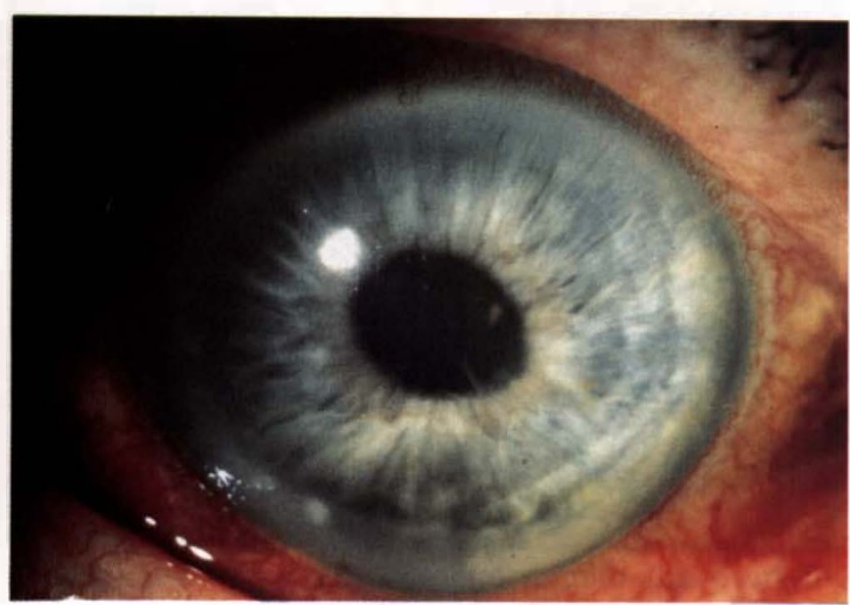

(e)

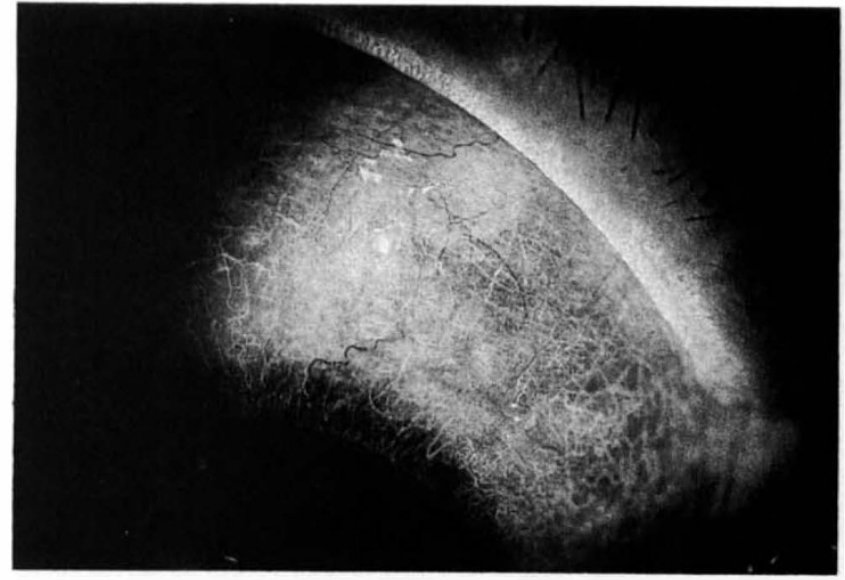

(b)

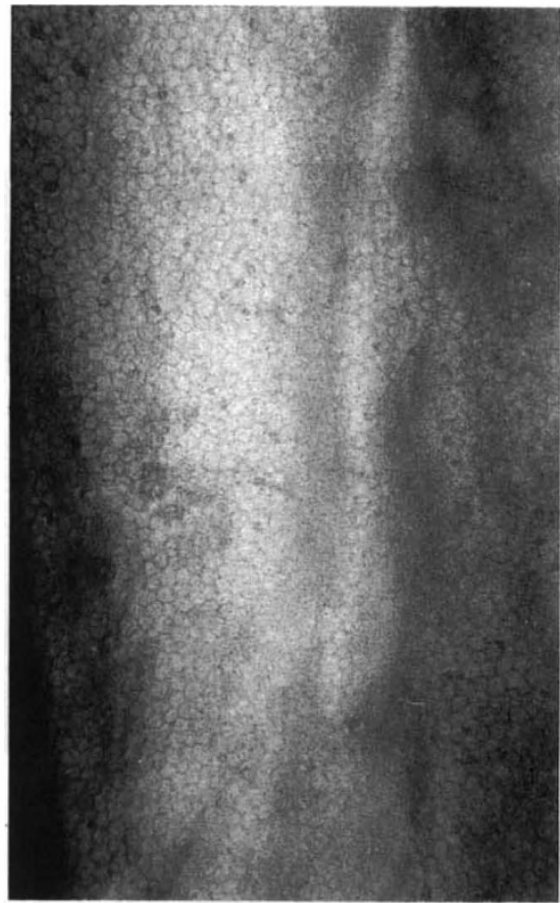

(d)

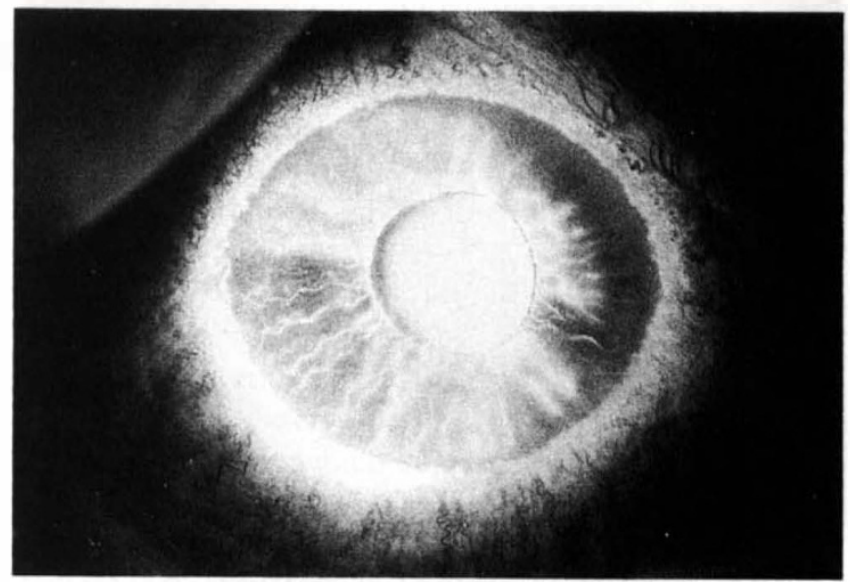

(f)

Fig. 3. (a) Episcleritis. (b) Fluorescein angiogram of episcleritis showing areas of poor vascular filling surrounded by dilated leaking episcleral vessels. (c) Acute disciform keratitis. (d) Specular reflection of corneal endophthalmitis in disciform keratitis. (e) Distorted pupil in acute iritis. (f) Iris fluorescein angiogram of acute iritis. (Continues.) 


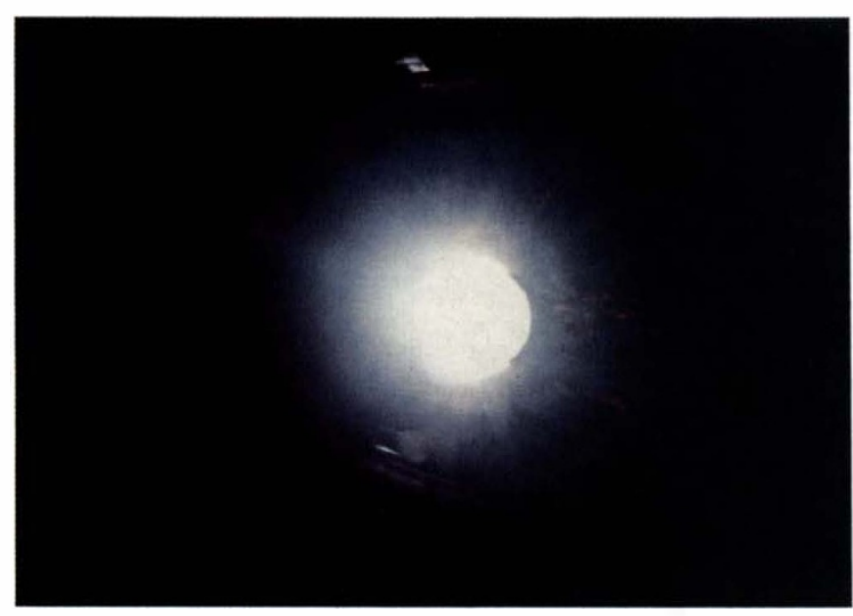

(g)

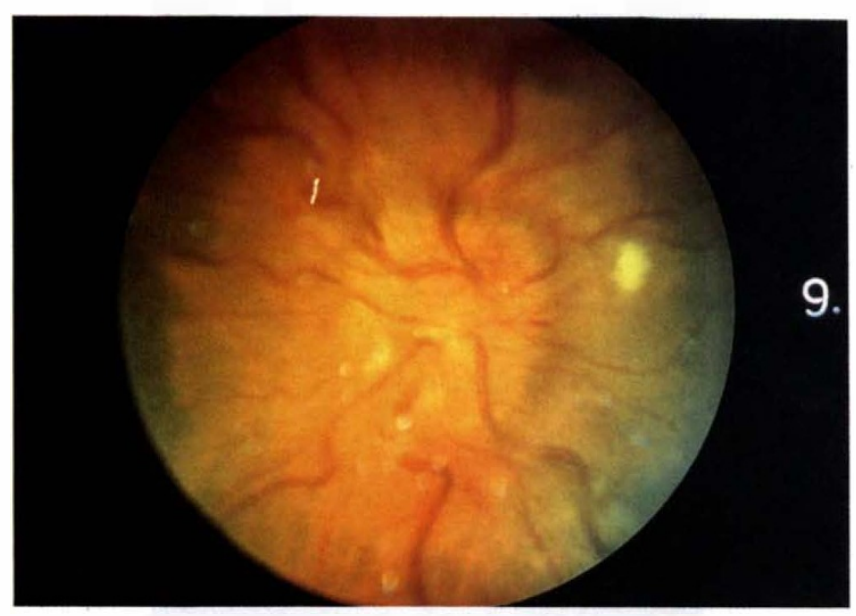

(i)

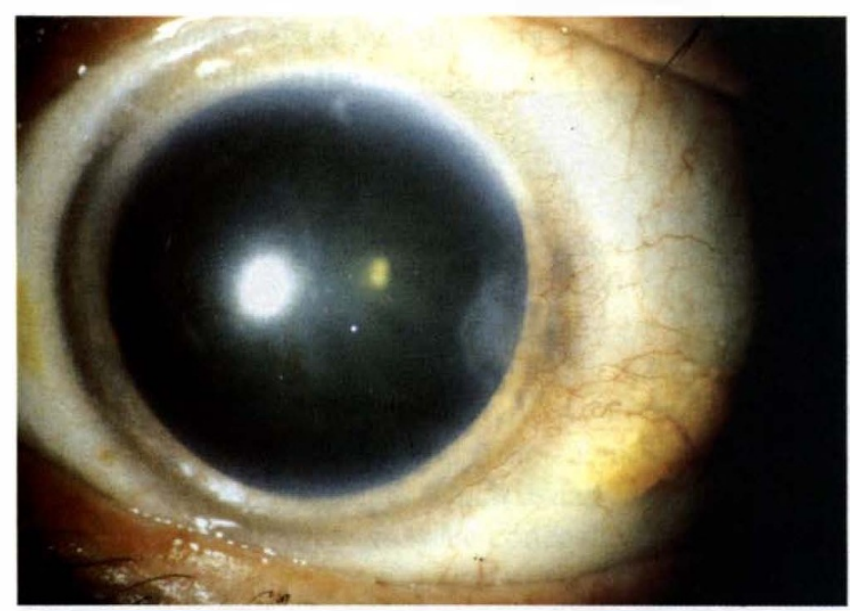

(k)

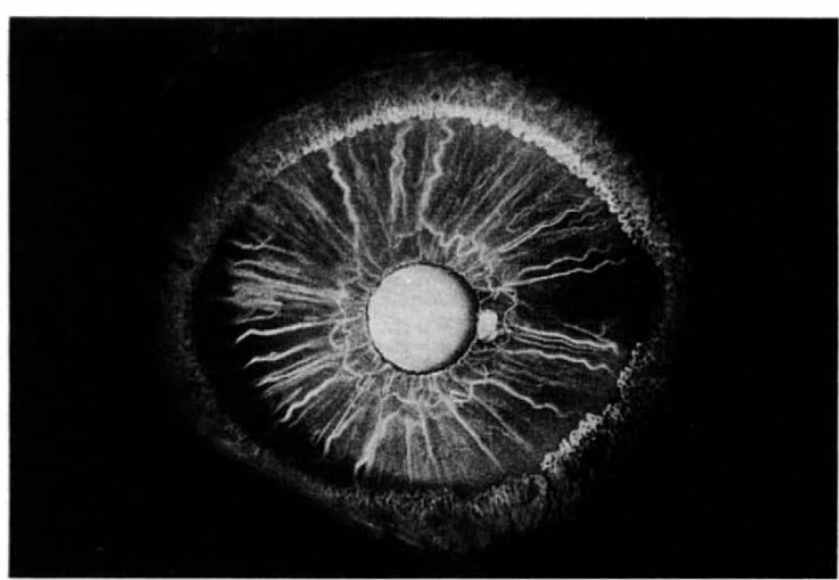

(h)

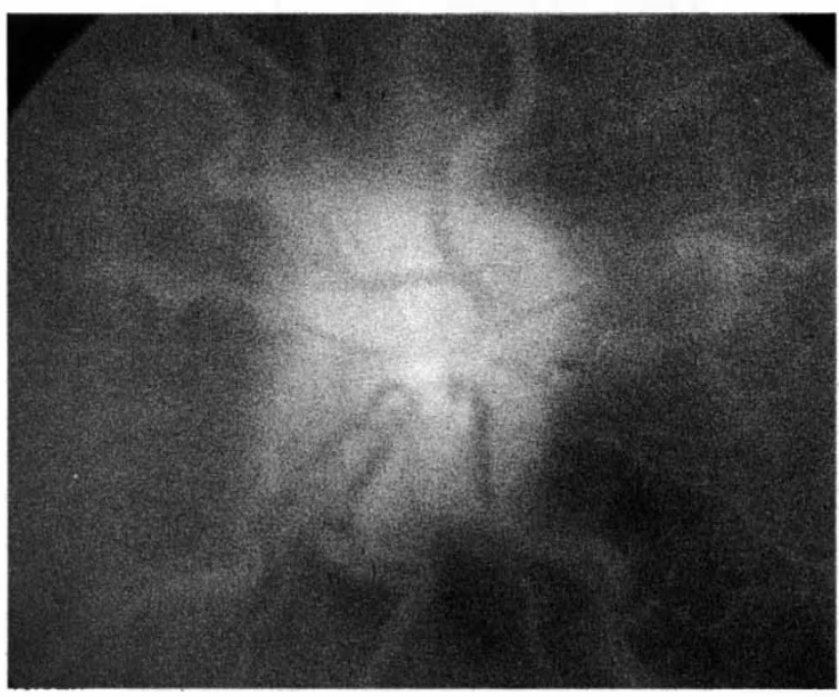

(j)

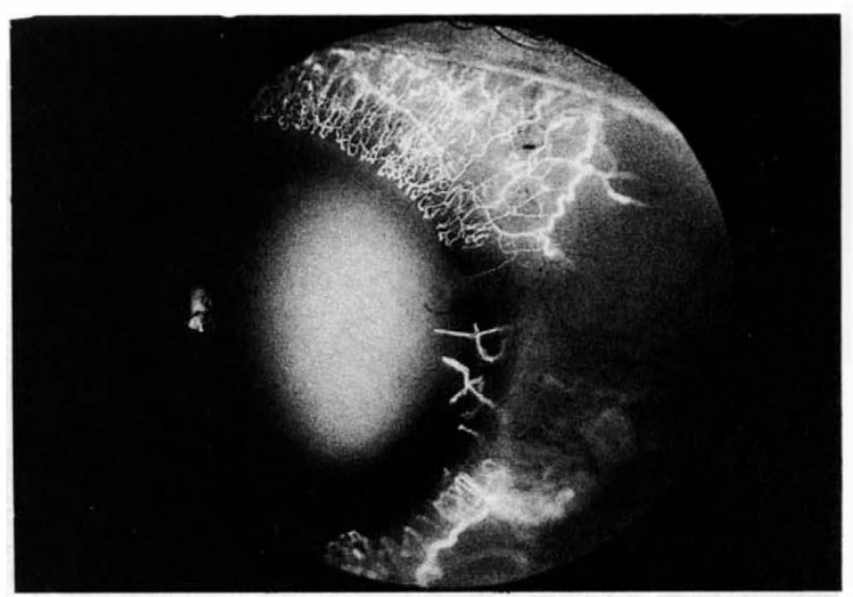

(l)

Fig. 3 (continued). ( $g$ ) Sectorial iris atrophy (4 weeks after zoster onset). (h) Iris angiogram of Fig. $3 g$. (i) Acute optic neuritis. (j) Late fluorescein angiogram of Fig. 3i. (k) Vascularised marginal chronic corneal stromal infiltrate. (l) Fluorescein angiogram of Fig. $3 k$ showing poor vascular filling of adjacent episclera. 


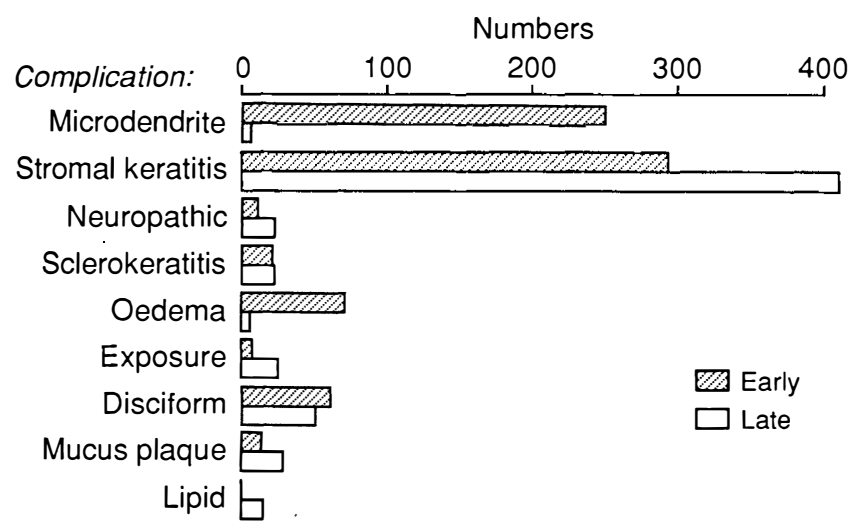

Fig. 4. Number of patients with corneal complications.

tective spectacles may be successful in preventing ulceration but tarsorrhaphy is the surest method. Neglected ulcers grow rapidly, with excavation and opacification of the stromal base and a distinct risk of severe secondary bacterial infection. Topical steroids are strictly contraindicated here as they tend to encourage the rapid excavation and growth of the ulcer; similarly bandage lenses have proved unsatisfactory in our hands, with 4 cases being complicated by corneal abscess and hypopyon formation. Temporary protection may be afforded by taping the eye closed with Blenderm (3M). Tarsorrhaphy, initially lateral third but sometimes subsequently central, has proved by far the most effective therapy, although ptosis induced by botulinum toxin is fast proving an attractive but very expensive alternative. ${ }^{20}$ Despite prompt treatment many cases heal with the slow formation of severe stromal scarring and large mucous plaque formation.

Sclerokeratitis (Fig. 5d) very rarely occurs (in only 35 of our patients) and may be accompanied by marginal guttering, sometimes called serpiginous keratitis. ${ }^{21}$ It responds well to topical steroid but tends to be indolent and so it is important that the dosage is adequate to control oedema and infiltrate.

Iris

Iritis is another common complication, occurring mildly in 551 patients, moderately in 157 and severely in 20 (Fig. 2). It appears within 2 weeks of the rash. ${ }^{22}$ It is characterised by very fine deposits on the corneal endothelium, faint flare, and a small to moderate number of cells. Often there is complicating ocular hypertension (possibly caused by an associated trabeculitis) and overlying corneal stromal oedema. All these features respond rapidly to topical steroids. In many cases pupillary distortion occurs 4-5 days after the onset of the iritis and fluorescein angiography reveals widespread dilation and leakage from iris vessels (Fig. 3e,f). A few days later iris atrophy commences, distinguished by sectoral loss of iris pigment epithelium and migration of pigment into the overlying stroma. At this time angiography shows areas of ischaemia coinciding with the areas of atrophy ${ }^{21}$ (Fig. 3g,h), which has been confirmed histologically as an occlusive vasculitis. ${ }^{23}$ The atrophy is readily seen by transpupillary transillumination, especially in blue irides, and is distin- guished by a rather moth-eaten sectorial distribution. In $12 \%$ of cases there is permanent iris sphincter damage. ${ }^{22}$

\section{Glaucoma}

The glaucoma observed in the acute phase of herpes zoster is due to hypertensive iritis and is exquisitely sensitive to topical steroid. We recorded 194 cases of glaucoma and an additional 42 cases related to topical steroid usage.

\section{Choroid}

Although choroiditis has been described, ${ }^{24}$ we have not seen a case. Neither have we seen choroidal detachments. ${ }^{25}$

\section{Retina}

We have seen 1 case of retinal pigment epithelial degeneration. It was interesting that although the scarring appeared quite substantial and was centred around the macula there was very little diminution of vision.

Retinal vasculitis ${ }^{26}$ has been described in both the living and the post-mortem eye. Whilst we have seen the occasional case of branch and central retinal vein occlusion we have not been persuaded by the temporal relationship or numbers that there is any connection with zoster. Earlier reports may, in fact, be referring to acute retinal necrosis.

Acute retinal necrosis has been well described with both ophthalmic zoster and zoster at other sites. ${ }^{27}$ There seems to be a defined pattern of retinal involvement in AIDS and this consists of a multifocal progressive chorioretinitis ${ }^{28,29}$ which rapidly leads to profound visual loss. The only treatment available is systemic acyclovir, which has a variable influence on the course of the disease.

\section{Neurological Lesions}

Optic neuritis is well documented ${ }^{30}$ and occurred in only 6 of our cases. It is probably ischaemic, is often accompanied by posterior scleritis, and has a poor prognosis for vision. Our fluorescein angiograms showed a close similarity to ischaemic papillitis (Fig. 3i,j).

External ocular muscle palsies are common, appearing in $31 \%$ of a large series of patients we screened orthoptically at the onset of the disease. ${ }^{31}$ However, only 42 of 58 patients complained symptomatically in our first series and 133 in our present series. All cranial nerves are involved, the IIIrd most commonly then the IVth and VIth. There are highly significant correlations with the severity of the rash, neuralgia and iritis. In 4 of our patients there was a total IIIrd nerve palsy accompanied by proptosis, scleritis and iritis which suggested orbital vasculitis. ${ }^{1,32}$ The majority of palsies recover subjectively within 3 months but an orthoptically detectable lesion remains. ${ }^{31}$ Palsies were ipsilateral in 34 cases, contralateral in 9, ipsilateral becoming contralateral in 6 and bilateral in 5 . The sites and aetiology of such lesions are difficult to construe; indeed they may be multicentric and mixed. They include: retrograde spread of virus from the ganglion to the nucleus 


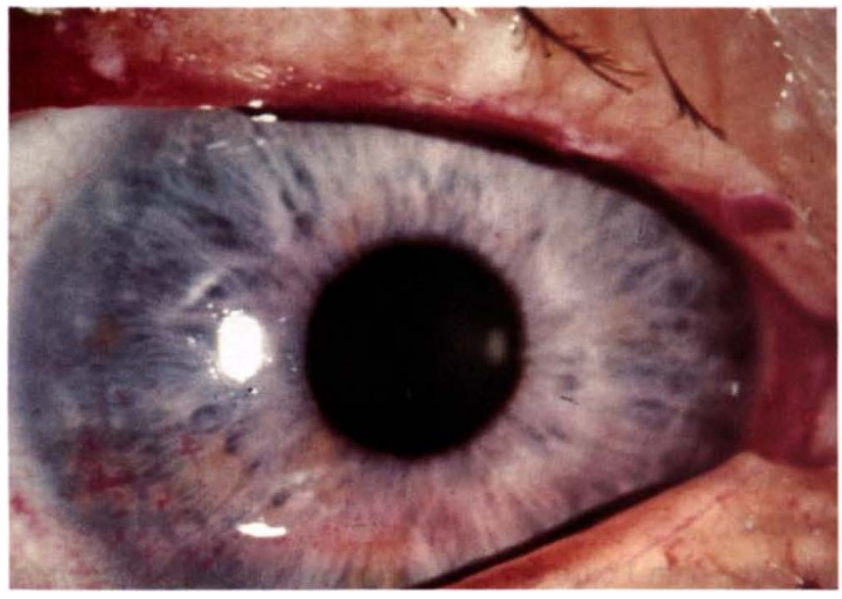

(a)

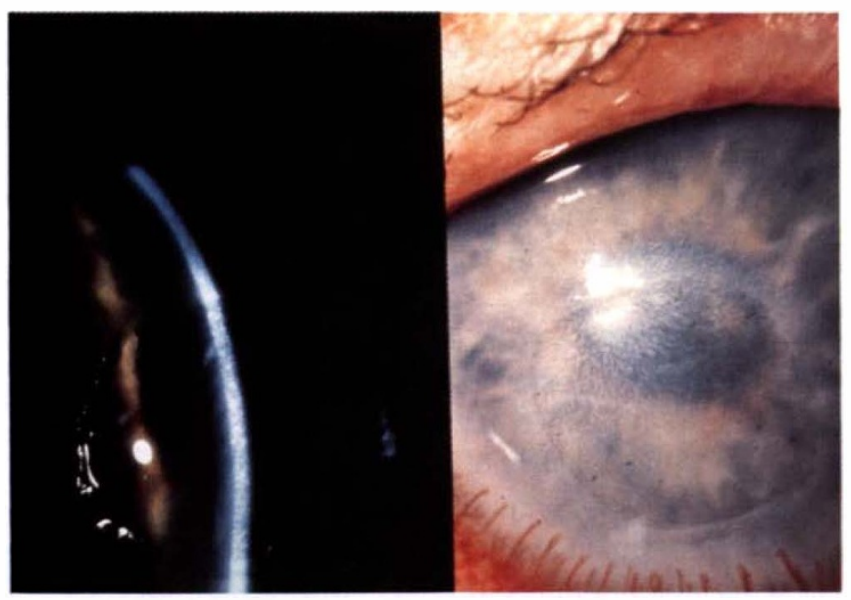

(c)

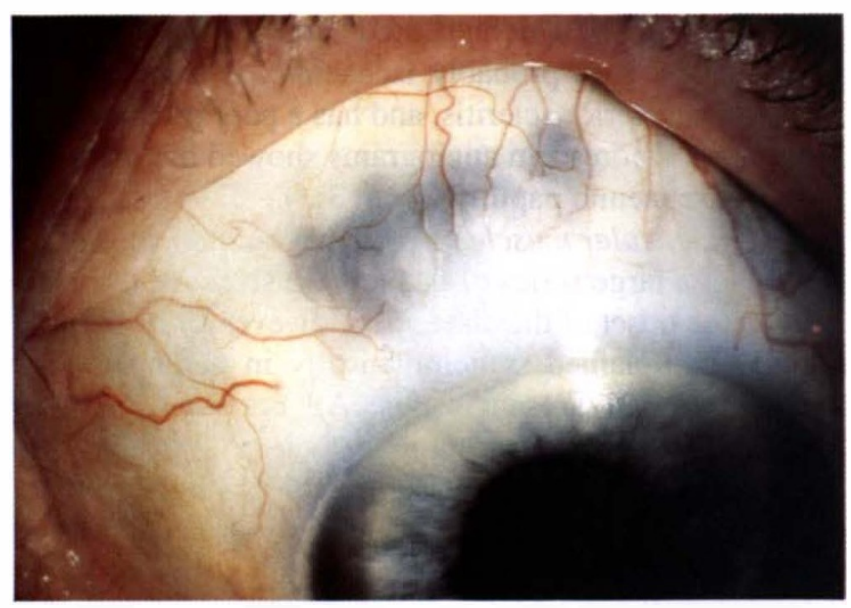

(e)

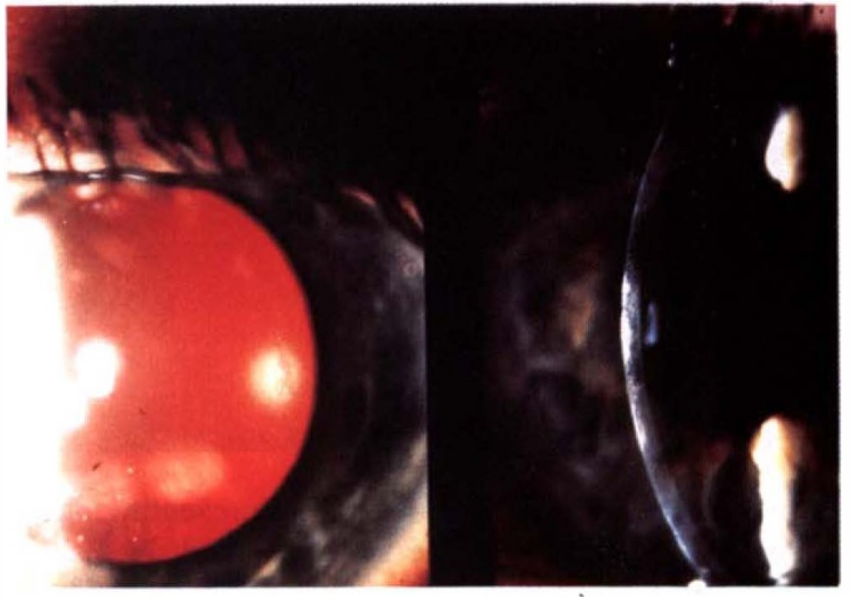

(b)

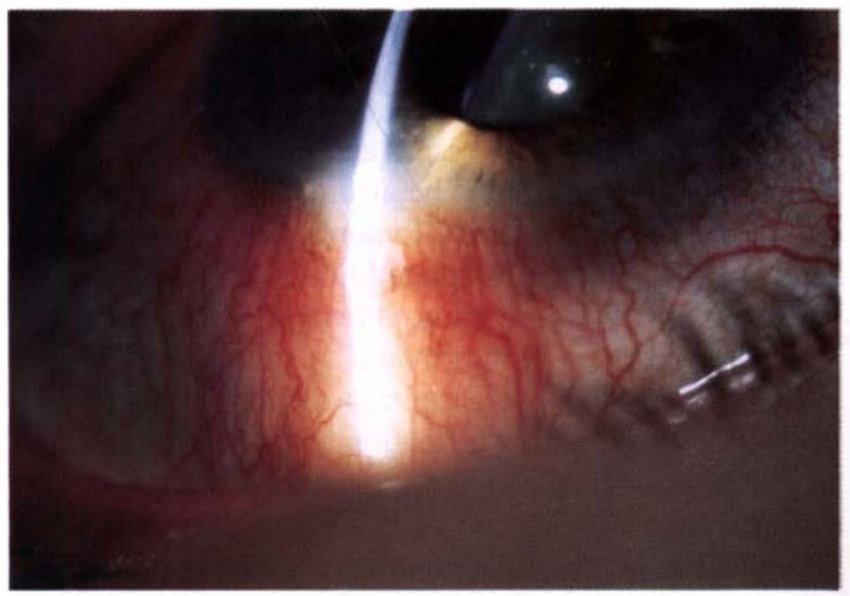

(d)

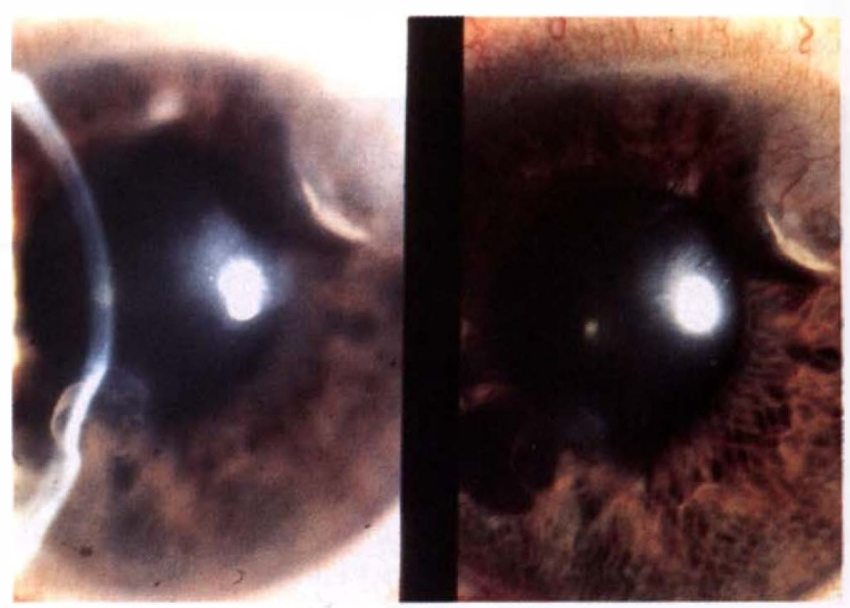

(f)

Fig. 5. (a) Acute epithelial keratitis stained with Rose Bengal. (b) Acute nummular keratitis: diffuse illuminator and slit view. (c) Acute neurotrophic corneal ulceration. (d) Acute sclerokeratitis. (e) Scleral atrophy in zoster. (f) Corneal facets following stromal infiltrates (diffuse illumination and slit). (Continues.) 


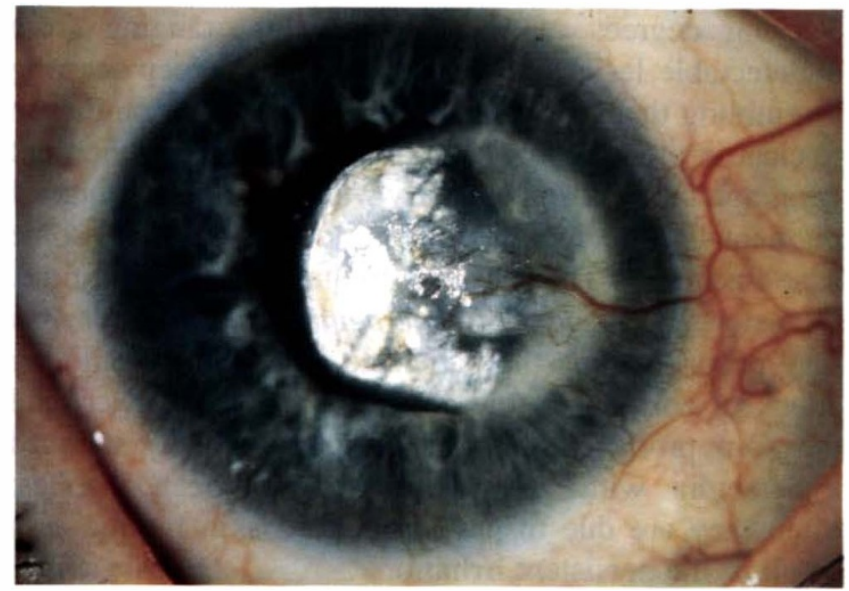

(g)

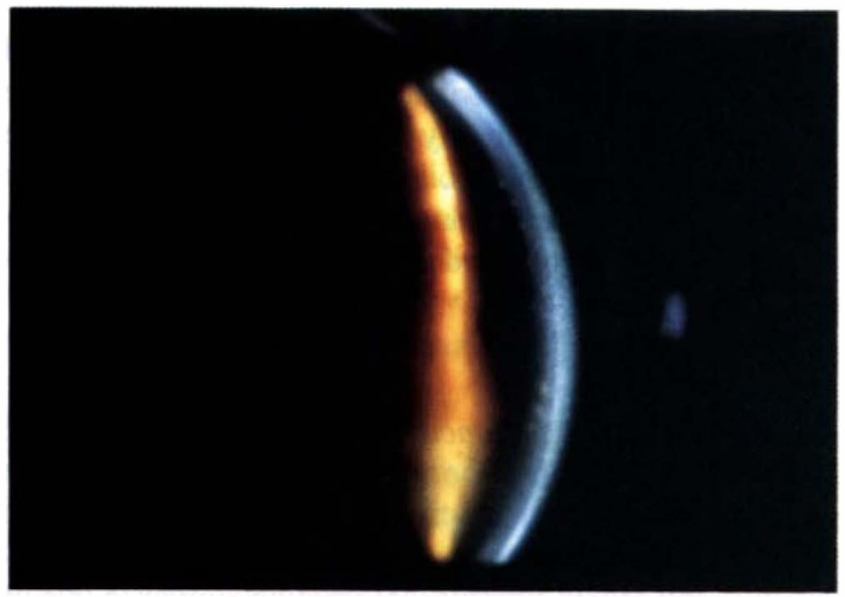

(i)

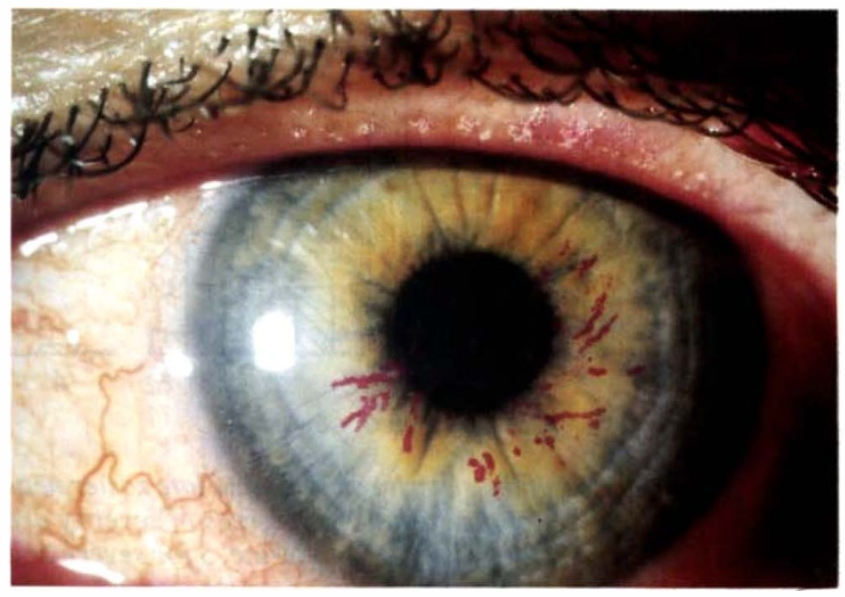

(h)

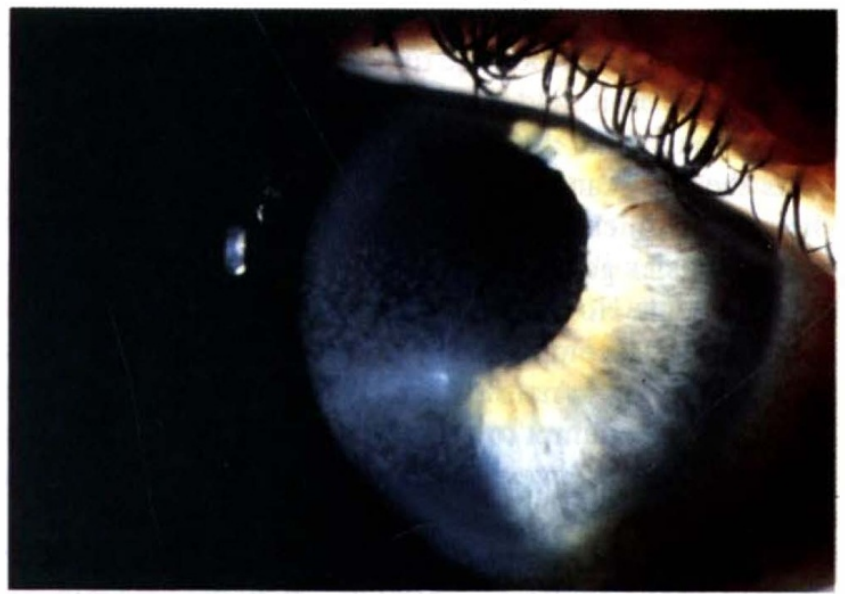

(j)

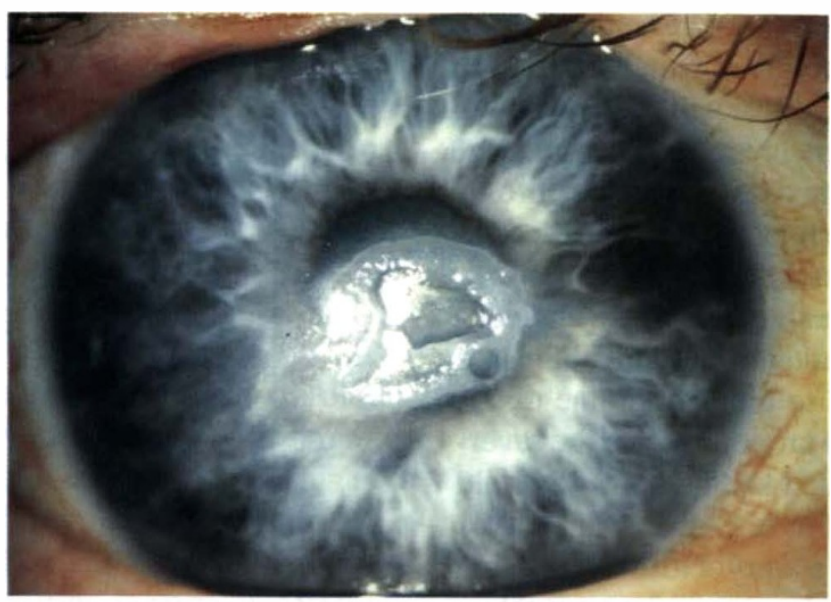

$(k)$

Fig. 5 (continued). ( $g$ ) Dense central lipid keratopathy following neglected disciform keratitis. (', ivucous plaque keratitis stained with Rose Bengal. (i) Mucous plaque keratitis to show interstitial infiltration and keratitic precipitates (slit view). (j) 'Exposure' keratitis showing ridge of swollen epithelium. ( $k$ ) 'Megaplaque' keratitis in zoster. 


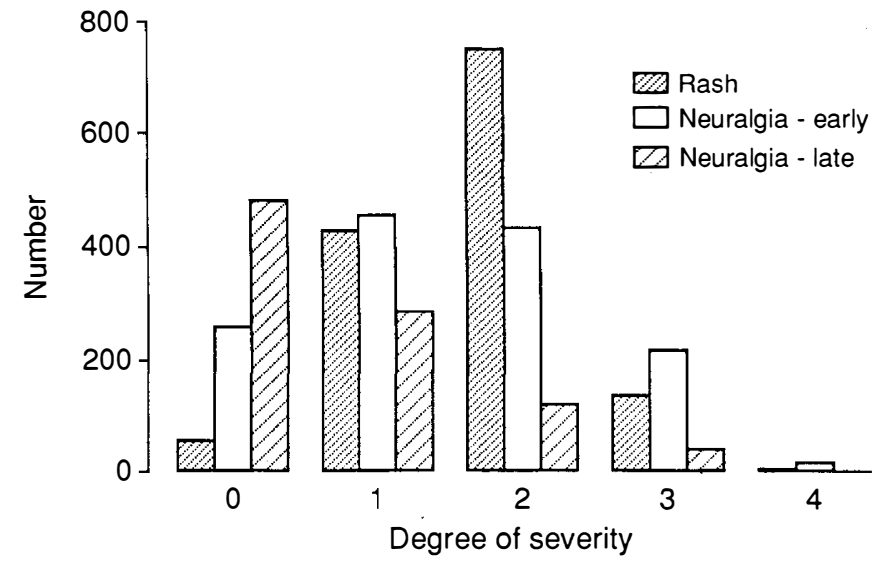

Fig. 6. Comparison of the severity of early and late zoster neuralgia and the severity of the rash. (The degrees of severity are scored as 0 for none, 1 for mild, 2 for moderate, 3 for severe and 4 for very severe.)

in the brain stem, a basal meningoencephalitis, a separate motor neuritis in the brain stem, an occlusive vasculitis involving either the pontine region or cavernous sinus and environs or orbit, and, lastly, possible myositis affecting the external ocular muscles. The latter seemed unlikely to us as the CT scans on 4 cases of total ophthalmoplegia showed no thickening of the muscles. External ocular muscle palsies generally recover subjectively and require no treatment. However, we feel that total third cranial nerve palsies accompanied by proptosis, posterior scleritis and possibly optic neuritis are best treated with systemic steroids in an attempt to prevent ischaemic damage to the optic nerve. We have tried retrobulbar triamcinolone in some of these cases with mixed results.

Rarely an ipsilateral VIIth nerve palsy occurs ( 7 in our series). Very rarely encephalitis develops, mainly in severe cases of herpes zoster with systemic spread of virus and a defective reticuloendothelial system: it is usually fatal and we have seen 2 cases. Another rare cerebral complication is contralateral hemiplegia, which occurs at about 7 weeks; patients usually recover well. ${ }^{33,34}$ We saw 7 cases. Recent investigations suggest a virus-induced granulomatous angiitis is responsible producing thrombosis of either large vessels such as the middle cerebral artery or small intracerebral vessels. ${ }^{35}$

At the onset of the disease neuralgia is severe and constant in the majority of cases, but tends to remit at the end of the first week. It is localised to the dermatome distribution of the rash and tends to be proportional to the severity of the rash. Of our patients, 252 had no pain, 454 mild transitory pain, 428 moderate pain, 212 severe pain and 11 very severe pain. There was a very close correlation between early neuralgia and rash severity/late neuralgia (chi-squared $p<0.01$ ) (Fig. 6). There was also a close correlation between neuralgia and loss of corneal sensation (Fig. 7). In many cases acute neuralgia is accompanied by a post-viral depression which comes on a week or two after the rash onset.

Table I compares the incidence of ocular complications in different series.

\section{Chronic Lesions}

\section{Skin}

Varying degrees of scarring develop, ranging from undetectable lesions to extensive areas of deep scarring resembling that seen after full-thickness burns, and even to cicatrix production. Generally, the typical punched-out geographical scars appear early with differing amounts of pigmentation or depigmentation, loss of hair, and some acne formation. These lesions frequently fade with time. Occasionally episodes of hyperaemia and recurrent rash may occur, leading the patient to think there is another attack of zoster. No true vesicles appear, however, and they are probably episodes of neurologically induced hyperaemia with secondary dermatological changes: often they are due to patient-induced skin trauma as a result of the persistent irritation.

\section{Eyelids}

Persistent ptosis is common and nearly always of mechanical aetiology due to chronic inflammation, oedema and scarring. Chronic blepharitis secondary to scarring of the lid margin is less commonly seen. Severe scarring of the lids may lead to trichiasis, loss of lashes, abnormal tear film distribution, ectropion, entropion occlusion of lacrimal puncta and notch defects. Extremely rarely fullthickness lid loss occurs.

\section{Conjunctiva}

Mucus-producing conjunctivitis is a common chronic lesion. This mucus is abnormal and adversely affects the tear film, making it greasy and unstable. Less often, large lipid-filled granulomas appear under the subtarsal conjunctiva and severe submucosal scarring similar to that of old trachoma can develop.

\section{Episclera and Sclera}

Scleritis and nodular episcleritis are particularly chronic

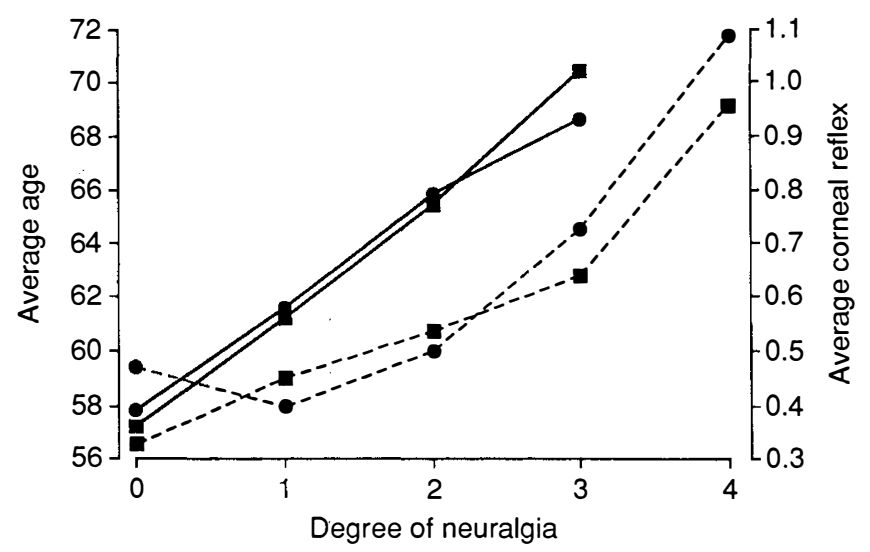

$$
\begin{array}{r}
\longrightarrow \text { - Age - early neuralgia } \\
\longrightarrow \text { Age - late neuralgia } \\
\longrightarrow C R \text { - late neuralgia }
\end{array}
$$

Fig. 7. Severity of acute and post-herpetic neuralgia in relation to the patient's age and corneal sensation. (Neuralgia is scored as 1 for mild, 2 for moderate, 3 for severe and 4 for very severe. The corneal sensation is scored as 0 for total loss, 1 for partial loss and 2 for no loss.) 
Table I. Comparisons of the incidence of ocular complications of ophthalmic zoster in different series

\begin{tabular}{|c|c|c|c|c|c|}
\hline & $\begin{array}{c}\text { Marsh and } \\
\text { Cooper }(n=1356)\end{array}$ & $\begin{array}{c}\text { Burgoon } \\
\text { et al. }{ }^{5}(n=36)\end{array}$ & $\begin{array}{c}\text { Womack and } \\
\text { Liesegang }^{36}(n=94)\end{array}$ & $\begin{array}{l}\text { Harding }^{37} \\
(n=71)\end{array}$ & $\begin{array}{l}\text { Scheie }^{38} \\
(n=93)\end{array}$ \\
\hline Conjunctivitis (\%) & 75 & 7 & & & \\
\hline Episcleritis (\%) & 55 & & & & \\
\hline $\mathrm{N}$ episcleritis (\%) & 5 & & & & \\
\hline Scleritis $(\%)$ & 5 & & & & \\
\hline Keratitis (\%) & 49 & 8 & 61 & 22 & 28 \\
\hline Microdendrites (\%) & 19 & & 51 & & \\
\hline Nummular $(\%)$ & 30 & & 41 & & \\
\hline Disciform (\%) & 5 & & 10 & 13 & \\
\hline Oedema $(\%)$ & 5 & & & & \\
\hline Mucous plaque (\%) & 3 & & & & \\
\hline Neurotrophic (\%) & 7 & & 25 & 4 & \\
\hline Exposure (\%) & 1 & & 11 & & \\
\hline Sclerokeratitis (\%) & 3 & & 1 & & \\
\hline Serpiginous $(\%)$ & & & 7 & & \\
\hline Iritis (\%) & 54 & 3 & 34 & 3 & 26 \\
\hline Glaucoma (\%) & 14 & & & 3 & 12 \\
\hline Muscle palsy (\%) & 10 & 3 & & 3 & 2 \\
\hline Optic atrophy (\%) & 0.04 & & & & 1 \\
\hline \multicolumn{6}{|l|}{ Neuralgia $(\%)$} \\
\hline Acute & 76 & 18 & & & \\
\hline Chronic & 21 & 10 & & & \\
\hline
\end{tabular}

and frequently leave patches of increased scleral translucency and scleral atrophy (Fig. 5e). Neglected sclerokeratitis runs a very chronic course with progressive deposition of infiltrate, vascularisation and lipid in the cornea which may either remain confined to the periphery to form a facetted type of scarring or may migrate across the cornea causing severe visual embarrassment.

\section{Cornea (Fig. 4)}

Nummular keratitis or superficial stromal infiltrates can behave like those of adenovirus type 8 in that they fluctuate in density, become chronically active and can diminish visual acuity. They are both exquisitely sensitive to low doses of topical steroid. Peripheral infiltrates if untreated may, over the years, consolidate and form facets (Fig. 5f) which show primary lipid deposition and can later become vascularised with secondary lipid deposition. It is notable that the adjacent episclera is relatively ischaemic (as demonstrated by fluorescein angiography: Fig. 3k,1). We feel in some cases a very small dose of topical steroid may be enough to prevent this scarring occurring. Infiltrates may rarely invade the central region of the cornea, profoundly reducing vision and necessitating corneal grafting.

Disciform keratitis, if untreated with topical steroid, nearly always becomes chronic with progressive accumulation of infiltrate in its centre and immune rings. This is followed by lipid deposition and vascularisation with very dense nebula formation (Fig. 5g), often adversely affecting vision. Here, too, corneal grafting is very successful because the corneal sensation is usually preserved. Unfortunately some cases evolve into a mucous plaque or neuroparalytic keratitis, ${ }^{39,40}$ both of which are unfavourable for grafting.

Neurotrophic keratitis may develop in the later stages of ophthalmic zoster with late loss of corneal sensation or decompensation of a previously quiet anaesthetic cornea
(23 in our series). Total loss of corneal sensation alone does not lead to this type of keratitis. Other factors are required, such as chronic conjunctivitis, lid margin deformities and loss of lid margin and bulbar conjunctival sensation. ${ }^{41}$ Chronic corneal epithelial swelling is seen first and leads to punctate epithelial erosions, ulceration in the interpalpebral area and infiltration of the underlying stroma. ${ }^{15}$ If untreated, either the ulcer tends to deepen and perforate or the underlying stroma becomes rapidly calcified (dependent on the state of the collagen, glycosaminoglycans, tear calcium and phosphate).

Neurotrophic keratitis is a very difficult management problem and patients must be carefully and frequently reviewed. The precorneal tear film must be stabilised by the use of artificial tears. Any coexisting ulcerative blepharitis should be treated firstly with lid toilet and antibiotic ointment; if this fails tetracycline tablets $250 \mathrm{mg}$ b.d. should be given. Abnormal plugs of mucus in the tear film may be dispersed by mucolytics such as acetylcysteine $10 \%$. In our own experience severe indolent ulceration of the cornea is best treated by a large lateral half tarsorrhaphy at an early stage, although taping of the lids and induction of a temporary ptosis with botulinum toxin may be tried first. We have been very impressed by the latter, ${ }^{20}$ but this facility is not available in many departments and recovery after tarsorrhaphy is remarkable, with stabilisation of the tear film and rapid healing of ulceration. A year or two after this procedure it may be possible to open the tarsorrhaphy in stages.

Mucous plaque keratitis. A strange form of keratitis developed in 44 of our cases of herpes zoster (13 within the first 6 months and 31 after that). It commences in two time periods: within the first 3 months (early) and after 6 months (late). It is characterised by transitory epithelial lesions followed by permanent stromal haze formation. The onset is sudden, with ciliary injection and the production of mucous plaque deposits on the surface of a dif- 
fusely swollen corneal epithelium. The overlying tear film becomes unstable and rapidly forms dry spots, often in dendriform shapes. The plaques look like fragments of white blotting paper and in the branching form often resemble dendritic ulcers. They stain brilliantly with Rose Bengal (Fig. 5h) and moderately well with fluorescein and Alcian blue. The plaques can easily be removed from the surface of the cornea without any damage to the underlying epithelium. They vary in size, shape and number from day to day and are accompanied by diffuse stromal haze in both the superficial and deep layers of the cornea. There is always underlying iritis with formation of small white keratitic precipitates (Fig. 5i). The plaques will usually resolve after treatment with $10 \%$ acetylcysteine drops and the underlying inflammation responds well to topical steroids. The keratitis progresses with loss of corneal sensation and increased stromal haze. After 3-4 months the plaques disappear and the tear film stabilises, revealing more clearly the large sheets of stromal haze which lead to a drop in visual acuity. In other cases there is late development of neuroparalytic keratitis or deposition of a ring of white surface plaque with gross reduction of vision. It is important to differentiate these plaques from the dendritic ulcers seen in herpes simplex. The features mentioned above greatly facilitate clinical diagnosis, but culturing of the epithelial lesions for virus clearly identifies herpes simplex from herpes zoster. ${ }^{42}$

The aetiology of mucous plaque keratitis is obscure. No virus has been cultured from these corneas but there does appear to be a connection with the prior use of topical steroids. ${ }^{43}$ In our series 11 of the early-onset and 21 of the late-onset patients had received them and disciform keratitis had preceded 6 of the 31 late-onset cases. ${ }^{40}$ However, the only significant correlation (chi-squared $p<0.01$ ) with any associated ocular lesions was with absent corneal reflex. It is vital to control the accompanying secondary glaucoma and surgery should not be delayed. Topical steroids treat the underlying iritis, mucolytics frequently clear the plaques, and artificial tears stabilise the tear film.

'Exposure' keratitis covers an ill-defined group of patients who show generalised corneal epithelial bedewing which often advances to grossly oedematous areas of epithelium with the formation of white ridges horizontally in the interpalpebral area. Rose Bengal and fluorescein give diffuse punctate staining with moderate linear staining along the ridges (Fig. $5 \mathrm{j}$ ). There is generally accompanying hyperaemia of tarsal and bulbar conjunctivae and always an extremely unstable tear film. Schirmer's test and tear production appears to be normal but plugs of mucus are often seen in the tear film. Strangely, corneal sensation is only partially lost, the lid margins may or may not be healthy and there is usually good blinking. The onset is usually just after the start of the rash but can be delayed. This type of keratitis runs a protracted course in which topical viscous agents are only partially effective. Some chronic cases may go on to develop large central white surface deposits and calcification, ${ }^{40}$ neurotrophic keratitis and permanent superficial stromal haze formation. Attempts can be made to stabilise the epithelium by intermittently taping the eye closed and lid hygiene, but the only therapy which appears consistently to stabilise the epithelium is a temporal third tarsorrhaphy. Dense plaques may have to be removed by superficial keratectomy ${ }^{44}$ (more recently with the excimer laser). We saw 25 cases in all. The aetiology is very obscure.

'Megaplaque' keratitis arises in some cases of mucous plaque and exposure keratitis. The plaques may be discshaped or ring-shaped and are attached to the underlying stroma by a narrow neck (Fig. $5 \mathrm{k}$ ). They profoundly interfere with vision and often there are epithelial defects around their base where secondary infections start. We have been impressed by the results of excimer laser superficial keratectomy in these patients.

Lipid keratopathy complicates severe cases of nummular, disciform and sclerokeratitis, especially when these are inadequately treated with topical steroids. Lipid keratopathy may occur in the absence of demonstrable blood vessels but dense deposits are always vascularised. The vessels may stem from the limbus at a narrow origin of a single artery and vein or from multiple stems all around the limbus. Unless their development is controlled with topical steroid or they are closed by laser the deposits increase. $^{45}$

\section{Iris}

Iritis often becomes chronic and, if untreated with steroid in the acute stage, posterior synechiae develop. The iritis may progress in its ischaemic manifestations to massive iris atrophy in $6 \%$ of cases. ${ }^{22}$ It is interesting that the iris changes sometimes seen after cases of acute closed angle glaucoma and following retinal detachment operations are similar and also due to iris vascular closure.

\section{Cataract}

Posterior subcapsular lens opacities and nuclear sclerosis often develop in severe and chronic cases of iritis. Rarely a sector of subcapsular lens opacity may underlie a sector of iris atrophy.

\section{Glaucoma}

Hypertensive iritis may persist with a minimum of flare and cells. Unfortunately, confusion can occur during the management of this condition when steroid glaucoma also develops and, indeed, was a problem in 42 of our patients. It is always worth considering the diagnosis of zoster in unilateral open angle glaucoma.

\section{Neurological Lesions}

Optic atrophy follows optic neuritis with a profound loss of vision: 6/60 and less. Permanent symptomatic external ocular muscle palsies rarely occur despite defects on the Lees screen, and when they do the affected muscle usually lies adjacent to an area of chronic scleritis and iris atrophy.

Post-herpetic neuralgia $(P H N)$ has been defined as pain 
developing after the crusts separate - variously described as starting at 4 weeks, 6 weeks, 2 months and 6 months. ${ }^{46}$ Because acute neuralgia usually ameliorates rapidly in the first month and a different type of PHN develops from 3 months, we chose this period for our definition. When measured at 6 months no PHN occurred in 478 of our patients, mild in 269 , moderate in 120 and severe in 31 (Fig. 6). It is correlated (chi-squared $p<0.01$ ) with rash, ocular involvement, loss of sensation and early neuralgia, but not age. It may take on different forms and can be a chronic constant pain or ache, an intermittent severe stabbing pain (closely resembling tic douloureux) or an intermittent very unpleasant paraesthesia or a sensation of crawling under the skin. The pain is often aggravated by touch, heat, cold winds and is worse at night. The majority of patients improve slowly over 1 year; the proportion who do not usually suffer depression and there may be severe exhaustion and even a danger of suicide.

\section{Recurrent Disease}

Perhaps the strangest aspect of ophthalmic herpes zoster is the recurrent nature of the ocular complications. These can reappear as late as 10 years after the onset of the disease and appear to be unrelated to the severity of the initial disease. They are frequently precipitated by the sudden withdrawal or reduction of topical steroid therapy. Episcleritis and scleritis often recur and can cause much resulting scleral atrophy. When nummular or disciform keratitis relapses there is an increase in stromal infiltrate, haze and thickness. Neuroparalytic keratitis is very prone to recur, with repeated disruption of corneal epithelium and ulcer formation. Mucous plaque keratitis also readily reactivates, with further formation of plaques, ciliary injection and iritis. Profuse cream-coloured keratitic precipitates usually accompany relapsing iritis, although hypertensive iritis may show practically no flare, cells or keratitic precipitates; in this it closely resembles PosnerSchlossman syndrome and can even mimic unilateral chronic open angle glaucoma.

It should be borne in mind that all these recurrent lesions may be separated by some time from a previous attack of herpes zoster and, indeed, the original attack may have been forgotten or so mild as to have passed unnoticed. It is therefore worth bearing the diagnosis of herpes zoster in mind when any of the lesions described above are seen in a patient for the first time, especially when old stigmata of zoster are apparent. These include the typical geographic skin scarring, the areas of increased scleral translucency or atrophy and the patchy iris atrophy.

\section{AETIOLOGY}

The current theory of aetiology is that, after an initial attack of chickenpox with its attendant viraemia, virus is retained in the posterior root ganglion in a latent form that later reactivates under the influence of unknown trigger factors, replicates, and migrates chiefly centrifugally down the sensory nerves. ${ }^{47,48}$ The virus eventually reaches the skin, where it produces the familiar herpes zoster ves- icles and, in some cases of ophthalmic zoster, the eye (it can be isolated from both $\operatorname{sites}^{49,50}$ ). It causes a perineuritis and perivasculitis in the affected dermatome and underlying areas leading to varying amounts of direct and indirect tissue damage.

\section{VIROLOGY}

Varicella zoster virus (VZV), or as it is now known, human herpes virus 3 (HHV3), is a typical herpes virus containing DNA, an icosahedral nucleocapsid and a glycoprotein-containing outer membrane. Under the electron microscope it is indistinguishable from the rest of the herpes family of viruses. Until recently it had not been possible to acquire enough pure virus to characterise its constituents, but the complete DNA sequence has now been elucidated. ${ }^{51}$ Using conventional methods there has only been one VZV strain detectable, but with the advent of restriction endonuclease analysis more are definable: this makes possible the tracing of virus in one host or within a population. Some of the genome is homologous with other herpes viruses ${ }^{52}$ and in a few cases amino acid sequences have been shown to be very similar to those of herpes simplex virus 1 (HSV-1). ${ }^{51}$ Most gene functions have not been elucidated as yet, except for the production of glycoproteins which reside in the outer coat and appear in the later stages of viral replication. Comparisons with HSV-1 also suggest evolution from an ancestral genome, so it is very likely that VZV gene products appear in a similar way to those of HSV, with an early phase (concerned with regulatory function), an intermediate phase (concerned with DNA synthesis) and a late phase (concerned with capsid and membrane synthesis).

Laboratory research on VZV has been sketchy, unlike that on HSV, because it is difficult to obtain cell-free virus and no satisfactory animal model has yet been developed. Both viruses are neuro- and epithelio-tropic, tending to cause direct cell damage in the acute stages: this is especially so for HSV. When they establish latency there is little evidence of cellular disruption but HSV seems to establish latency and reactivate more easily. Both viruses have humans as their only reservoir, HSV being more widespread with an endemic pattern, and VZV being more prevalent in urban societies and showing an epidemic pattern. The presence of antibodies as shown by sero-conversion in adult life approaches $70 \%$ for HSV and $95 \%$ for $\mathrm{VZV} ;{ }^{53,54}$ implying that virtually the whole population comes into contact with these viruses, although not all get clinical manifestations.

\section{EPIDEMIOLOGY}

The classic paper on epidemiology is that by HopeSimpson, ${ }^{48}$ which covers 192 cases of zoster seen in general practice: he found the incidence of new cases per population block to be $0.074 \%$ in those under 10 years of age, a plateau of $0.25 \%$ from 20 to 50 years of age, and over $1 \%$ over 80 years. In our series of over 1300 patients from the Zoster Clinic at Moorfields ${ }^{55}$ we found a slightly different pattern: a steady exponential rise rather than a 
dramatic increase in later life, though the figures are unreliable after 80 years of age. Hope-Simpson's cases came from general practice whilst ours are mostly from referrals to Casualty, so they may not be strictly comparable. We found no consistent changes with season, or with sex.

The weekly returns from the Royal College of General Practitioners (RCGP) give countrywide figures on zoster in general. ${ }^{55}$ Zoster incidence stays steady at $3-4$ per 1000 and does not follow the epidemic pattern of chickenpox, thus making it unlikely that zoster is an immediate result of contact with VZV. This is contrary to the old theory of aetiology in which close exposure to the virus was thought to cause a change in immunity resulting in reactivation of virus and an attack of zoster. It is also significant that at the vesicular phase of zoster close contacts who have not suffered from chickenpox risk acquiring the infection. The higher zoster prevalence rates in the older age groups are the opposite to that in chickenpox, but the age intervals provided by the RCGP are not sufficiently narrow to make any comparison with the Moorfields' figures. Females have a slightly lower incidence for chickenpox and a higher one for zoster than males. AIDS, Hodgkin's disease and other conditions causing impaired cellmediated immunity are associated with a higher incidence and severity of the clinical disease. Varicella in the first year of life leads to a high incidence of a mild variety of zoster within the next year or so. ${ }^{14,56}$ Second attacks of herpes zoster occur in $4 \%$ of patients ${ }^{8}$ and two areas of the body can be affected simultaneously.

\section{IMMUNOLOGY}

It is often stated that the development of zoster is associated with a temporary depression of immunity and so there have been many studies in zoster.

\section{Humoral immunity}

It has been known for many years that there is an anamnestic rise in the level of varicella-neutralising antibody during an attack of herpes zoster, demonstrating that the virus had been encountered previously. ${ }^{57}$ There is typically a rise in immunoglobulins $\mathrm{G}$ and $\mathrm{A}$ within 2 days of rash onset, reaching a peak in 2-3 weeks, and declining to very low levels at a year. ${ }^{58,59}$ There is an elevation of immunoglobulin reported in some series; this usually indicates a primary infection and suggests that although the antibody pattern of response to zoster has components similar to varicella there are some additional ones which make it distinct. ${ }^{60}$ The outcome of varicella, either as zoster or chickenpox, does not seem to be adversely affected by the absence of serum antibodies,${ }^{61}$ whereas those with Hodgkin's disease, who have normal antibody levels, usually do badly. The consensus is that other, presumed cellular factors are more important. Antibody localisation may, however, be important in causing some of the pathological findings, such as the granulomatous angiitis thought to be associated with orbital involvement, ocular muscle palsies, iritis, episcleritis/scleritis, stroke, ischaemic optic neuropathy and encephalitis: the mechanism may well be a type 3 hypersensitivity.

\section{Cellular Immunity}

Cellular responses to VZV have also been studied extensively and reveal a consistent depression of cell-mediated immunity in the first 5 days of the zoster rash as assessed by blastogenesis of peripheral blood cells and reduced delayed-type sensitivity response to skin testing. ${ }^{53}$ It is possible that this is either a true depression of cellmediated immunity or is due to recruitment of immunologically competent cells into affected tissues so that they are not available in the circulatory pool. A reversal of T4/T8 subsets in the peripheral blood has been noted ${ }^{62}$ and this could be either due to reduced circulating number of CD4+ T cells or to increased numbers of circulating CD8+ $\mathrm{T}$ cells.

Cytotoxic $\mathrm{CD} 8+\mathrm{T}$ cells are important in destroying virally affected cells. These CD8+ cells can become activated when their receptor recognises viral antigens in combination with class I HLA antigens on the surface of the infected cell. Activation of CD8+ cytotoxic T cells results in target cell death by membrane cell lysis after secretion of substances such as perforin by the activated $T$ cells. CD4+ cells are necessary for the maturation of cytotoxic $\mathrm{CD} 8+\mathrm{T}$ cells and for the production of specific neutralising antibody by B cells maturing into plasma cells, which occurs as a result of secretion of lymphokines such as interleukin-4.

\section{PATHOGENESIS}

Herpes zoster is a reactivation of latent VZV, in a similar way that cold sores are of HSV.

\section{Latency}

HSV and VZV are thought to become latent in the primary attack, being transported from the epithelial vesicles along the sensory axons to the neural cell body. ${ }^{63,64}$ This has been demonstrated in animal models for HSV, and in the main depends upon the amount of virus. ${ }^{65,66} \mathrm{~A}$ similar process has been inferred for VZV, because the frequency of dermatome involvement in zoster parallels that of rash density in chickenpox, being most common on the trunk and head. Latency occurs in only a small fraction of neurones, and involves the incorporation of viral genome into the host one; whether this is in a specific site, randomly, or whether there are several sites in each cell is not known (with HSV it is an extrachromosomal DNA in the circular episome). VZV RNA and DNA have been demonstrated in cadaver trigeminal ganglia, at a rate of $1 / 1000$ neurones. ${ }^{67}$ To date the same strain of virus has been shown to appear in separate sites during zoster ${ }^{68}$ and probably at the primary and recurrent stages. ${ }^{69}$

\section{Reactivation}

The mechanisms of reactivation in HS and VZV are likely to be similar and relate to the symbiosis of the virus and host: a disturbance of this causes clinical and possibly subclinical disease. Many factors may cause HSV to break out of latency, and it has a much greater inherent potential for 
doing this than VZV: this might be related to the position of insertion, quantity of viral genome or proliferative potential. Traditional hypotheses of reactivation involve alterations in the immune system with time, trauma and neural degeneration.

\section{Reduced Immunity}

Hope-Simpson ${ }^{48}$ suggested that when the titres of antibody or reactive cells fall below a certain level, the virus somehow escapes and causes clinical damage. There is no good evidence for this in humans for either virus. After the primary infection with VZV, circulating antibody levels fall off over a year and become undetectable..$^{53}$ Titres do not consistently decrease with age, as is required if this is to be the main determinant of disease, and there is an anamnestic response in the majority of individuals who have zoster, implying that immunity has not faded. Moreover, those who have suffered zoster early in life are not more likely to have a second attack after a lesser interval than others who get their first attack in middle age (as might be expected if the fall in titres was host-dependent). Cell-mediated responses also decrease with age but we are not aware of any research which has demonstrated this for VZV in particular, and the predominantly lymphocytic infiltration into trigeminal ganglia during the acute phase indicates that cells may certainly be induced to respond specifically and with effect.

\section{Trauma}

It seems that damage to part of the neurone or iontophoresis of various chemicals reliably lead to reactivation of $\mathrm{HSV}^{54}$ and recovery of virus from tissue is difficult unless there has been a certain amount of damage, such as in explantation. ${ }^{70}$ It is interesting that mild and transient attacks of herpes zoster can follow retrobulbar or trigeminal ganglion injections and neurosurgical incisions (socalled symptomatic zoster). ${ }^{71}$ Equally exposure to ultraviolet light, nerve section and irradiation are well known to reactivate HSV. Neuronal metabolism in the adult is mostly concerned with maintenance of the cell and there is virtually no proliferative activity: most of the DNA is inactive. If the cell is damaged in some way, such as by sectioning the axon, repair mechanisms start and it is feasible that the viral DNA may be involved in this process, leading to switching on of viral proliferation which may or may not overwhelm the cell and lead to viral shedding. The likelihood of this happening with VZV is small because of the very low frequency of neurone colonisation; VZV's potential for reactivation is also low, but over a lifetime the chances of viral shedding could well be significant. What is difficult to explain is why in typical zoster, unlike in herpes simplex, the neurones are completely destroyed and there is no potential for recurrence. It is perhaps at this stage that the immune system is important: the frequent recurrences of HSV shedding keep the immune response active and control local spread very quickly, but as VZV recurrence is very infrequent, the response is probably delayed allowing more viral spread in the gan- glion and a more vigorous tissue response when it eventually occurs.

\section{Other Factors}

Neurones may be damaged by other factors, for instance HIV infections; clinically HSV is often reactivated by colds, influenza and pneumonia which may have a direct effect on neuronal metabolism, rather than indirectly by a specific immune response. So far there is no evidence that other acute infections precipitate zoster.

\section{Ageing}

Most episodes of zoster cannot be related to a precipitant and occur chiefly in older age groups. It is possible that a latently infected cell is involved directly or indirectly by the normal neuronal death rate and so sets off the process of reactivation: an intellectually satisfying idea for which there is as yet no evidence. Against it is the fact that zoster can present at any time of life: the Zoster Clinic incidences, showing a form of exponential rise with age, might, however, be explained by an appropriate statistical model.

\section{Ocular Pathogenesis}

There is undoubted viral replication in the acute phase of the disease, as confirmed by the culture of virus from corneal epithelial lesions ${ }^{50}$ and there may or may not be replication in the stroma, endothelium, iris and retina. Once virus reaches the tissues acute and chronic inflammatory processes attempt to clear virus and viral antigens; the dose and strain of virus, efficacy of immune response, tissue involved and treatment are some of the governing factors. Inability to clear virus and the establishment of a type of chronic, low-grade infection is probably the main feature of the long-term problems (apart from acute damage such as denervation). Whilst we have been unable to grow the virus in chronic keratitis from either corneal epithelial scrapings or scarred corneal discs removed in keratoplasty and submitted to maceration, recently, viral DNA has been found in post-mortem eyes within the neurovascular bundles and corneal buttons. ${ }^{72}$ We feel that during remissions of inflammation VZV is in the latent form and there is a minimal tissue response, but when chronic inflammation occurs there may be an alteration of viral DNA or a sort of autoimmune response by the host (but no viral replication as we know it). In this way it differs from HSV.

\section{PATHOLOGY}

There is relatively little in the literature on the pathology of zoster. Perhaps the earliest paper is by Head and Campbell $^{73}$ describing inflammation, haemorrhage and necrosis of ganglion cells in the dorsal root ganglion followed by scarring. They stressed the marked variation in the severity of the lesions paralleling clinical experience. As far as we know there is a very short phase of viral replication in the nerves and closely related tissues at the onset of the disease. This is followed shortly afterwards by infiltration 
with inflammatory cells and then by variable necrosis of cells - principally neurones. There may then be resolution or continuing chronic and relapsing inflammation persisting for many years with continuing damage to the tissues and scarring. The trigeminal ganglion, brain, peripheral nerves, orbit and globe have been examined.

\section{Trigeminal Ganglion}

Virus has been isolated in the very early stages $;{ }^{74}$ within 2 weeks there is infiltration with polymorphonuclear granulocytes, plasma cells and predominantly lymphocytes. ${ }^{75}$ The latter suggests that there is already a coordinated cellmediated response rather than a purely inflammatory one. ${ }^{76}$ The adjacent dural sheath and carotid are involved in the inflammatory process. Early on there is a varying amount of neuronal necrosis; indeed, in some patients practically all the cells may be destroyed. ${ }^{73}$

\section{Brain}

The mesencephalic nucleus may show large nodular collections of microglia with later effacement of structure. There may be a lymphocytic leptomeningitis and lastly the cranial nerves and their nuclei on both sides may show lymphocytic infiltration. ${ }^{77}$

\section{Peripheral Nerves}

At the onset there is a perineuritis with an adjacent perivasculitis. About 10 days later there is secondary decay of axons and myelin sheaths followed by fibrosis.

\section{Orbit}

There can be extensive vasculitis, haemorrhage, perineuritis and inflammatory cell infiltration of other orbital contents including the extraocular muscles.

\section{Globe}

Most pathological reports are of the later stages of the disease when the eye had been enucleated. ${ }^{78}$ The commonest findings are perineuritis and perivasculitis in the scleral channels, in the long and short ciliary nerves and in the arteries. Presumably the virus reaches the eye via the ciliary nerves. The connection between this and subsequent chronic inflammatory reactions has not been clarified. ${ }^{78}$ Although viral replication has not been demonstrated, in late phases of the disease viral DNA has been found. The vasculitis is probably due to immune complexes, with the antigen in the nerve fibre bundle and the antibody in the adjacent blood vessel ${ }^{22}$ (an Arthus phenomenon). It is interesting that, at times, lesions of different tissues develop in the same sector of the eye, ${ }^{79,80}$ confirming the neurological distribution of the disease in the globe.

\section{TREATMENT}

Ophthalmic herpes zoster offers a great challenge in management. Such is the nature of the complications that effective treatment early in the disease can prevent many disasters at a later stage. Of necessity, treatment must be intensive at first and in many cases must include a longterm follow-up. The objectives of treatment are twofold: to stop viral replication at the earliest opportunity and to control the ensuing inflammatory changes, thus minimising tissue scarring.

\section{Systemic Therapy}

\section{Short-Term Admission}

Short-term admission (5 days) is recommended for those with severe disease, the aged, the immunosuppressed, and those with poor social circumstances. If admission is impossible, there should be 1 week's bed-rest at home with good nursing. Proper diet, care and administration of therapy is usually successful in obtaining rapid recovery. The patients should be barrier-nursed in a side ward during the vesicular stage and those with no previous infection by varicella should be kept away until all vesicles have gone. After this they are no longer infective. Patients are of ten distressed and frightened of the disease and must be reassured that the acute stage is short-lived and recovery usually rapid with the correct management.

\section{Steroidal Anti-inflammatory Drugs}

The routine use of systemic steroids in patients with ophthalmic herpes zoster is controversial. ${ }^{81}$ Although some physicians use systemic steroids routinely, claiming a lessening of zoster complications, in particular $\mathrm{PHN},{ }^{82,83}$ others stress the increased risk of systemic spread of the disease with high doses.$^{84,85}$ It should be pointed out that most adverse reports of this treatment were in patients previously immunosuppressed. There are, of course, the routine complications caused by systemic steroids in old people such as gastric ulceration, hypertension and psychosis. There is no doubt that the potent anti-inflammatory properties of steroids are very valuable for the vasculitis which occurs in the skin, eye, orbit and brain. It has also been claimed that the incidence and severity of postherpetic neuralgia are significantly reduced. We therefore feel that systemic corticosteroids are indicated very early in patients with: (1) large haemorrhagic skin bullae, (2) progressive proptosis with total ophthalmoplegia, (3) optic neuritis and (4) cerebral angiitis. Untreated, the first leads to severe skin scarring and neuralgia, the second to continuing diplopia, the third to severe optic atrophy and the fourth to hemiplegia. An initial oral dosage of $80 \mathrm{mg}$ prednisone should be given, which may be rapidly reduced by $10 \mathrm{mg}$ per day to a $5 \mathrm{mg}$ maintenance dose. ${ }^{86}$

\section{Non-steroidal Anti-inflammatory Drugs}

Oral Flurbiprofen (Froben, Boots) $50 \mathrm{mg}$ t.d.s. is useful in cases of episcleritis; scleritis and sclerokeratitis. We have been impressed with its use alone in episcleritis, where the dose must be slowly reduced as improvement occurs and there is less likelihood of a recurrence than with topical steroids. However, in cases of scleritis and sclerokeratitis it must be used in combination with potent doses of topical steroids. The anti-inflammatory property of some analgesics is a possible useful adjunct here. 


\section{Antiviral Drugs}

Systemic antivirals have proved rather disappointing in zoster. IDU is far too toxic for systemic use, cytosine arabinoside proved less effective than the control in one clinical trial ${ }^{87}$ and adenine arabinoside too insoluble to introduce intravenously in an effective dose without fluid overloading. ${ }^{88}$ Despite extravagant claims for amantadine $^{89}$ there have been no adequate controlled studies on its effectiveness. Acyclovir, although not as effective in vitro against varicella/zoster as against $\mathrm{HSV}$, has been extensively used and has proved effective in reducing the rash duration, spread and acute herpetic neuralgia in immunosuppressed patients. ${ }^{90}$ It has also been used in the treatment of varicella/zoster acute retinal necrosis with mixed results. ${ }^{27}$ The drug is administered intravenously at $10 \mathrm{mg} / \mathrm{kg}$ over 1 hour repeated every 8 hours for 7 days, then orally at $800 \mathrm{mg} 5$ times a day. The results of oral and intravenous courses of treatment in immunocompetent patients are controversial; although acute neuralgia and rash healing time are marginally improved ${ }^{91-94}$ reports of its effects on the incidence of post-herpetic neuralgia are conflicting. ${ }^{95}$ There is one large controlled series showing a reduction in ocular complications in patients who were treated within 72 hours of developing the rash, but where all those with ocular complications at presentation were excluded. ${ }^{96,97} \mathrm{We}$ feel that before substantial funding is used to finance use of the drug routinely in zoster more clinical trials are essential.

The search must continue for a more effective antiviral agent, but if viral replication is confined to the onset of the disease and if the later lesions are, as seems likely, due to immunologically mediated reactions not dependent on the presence of live virus (as we know it), the outcome will not be improved unless the antiviral is administered at the very onset of the disease.

\section{Antibiotics}

In our experience antibiotics have no value in the treatment of acute zoster. The early oedema and crusting are due to viral-mediated damage rather than secondary bacterial infection.

\section{Analgesia}

Fortunately, acute neuralgia, although at its most severe within the first 2 weeks, is usually short-lived. Full analgesia should be given in the early stages because there is increasing evidence that when administered at this stage it reduces permanent damage to the nervous pathways. It is best to start with milder analgesics and rapidly build up to stronger ones as necessary: for instance paracetamol by itself or in combination with dextropropoxyphene hydrochloride (co-proxamol), or dihydrocodeine (DF118). In very severe cases pethidine may be necessary. Buprenorphine tends to make patients feel drowsy and disorientated, especially the elderly, and is therefore best initially used at night only, although if very effective it can be tried at a dose of half a tablet during the daytime.

Post-herpetic neuralgia is extremely difficult to treat and, like acute neuralgia, is more of a problem in older patients. The pain and paraesthesia tend to be worse at night and are aggravated by heat and cold, wind and touch. These provocations should be avoided where possible; failing that extra analgesia may be needed at these times. The remedies recommended in the literature are legion (many anecdotal and rather dubious) and range from posterior pituitary extract to snake venom. The list clearly demonstrates the overall failure of treatments for this condition. Contrary to others we have found carbamazepine $100 \mathrm{mg}$ twice a day disappointing in the tic douleureux type of post-herpetic neuralgia. Chlorpheniramine (Piriton, Allen \& Hanburys), $4 \mathrm{mg}$ t.d.s. and chlorpromazine $25 \mathrm{mgm}$ t.d.s. have proved useful with severe irritational paraesthesia. Unfortunately in our experience nothing seems to ameliorate the severe pain.

\section{Antidepressants}

Post-viral depression of ten begins during the acute phase of zoster and may also be an important component of chronic post-herpetic neuralgia. It is important to recognise it and treat promptly with tricyclic antidepressants such as amitriptyline (50 mg twice a day). ${ }^{98}$ Its existence should be explained to patients and they should be reassured that it responds well to treatment and will pass.

\section{Supportive Counselling}

Patients in the acute phase should be reassured that tissue swelling will rapidly subside and, in most cases, the pain improve. They should be warned that a long convalescence may be necessary. Those with severe chronic PHN not responding to treatment should be offered counselling in an attempt to help them live with the pain.

\section{Chickenpox Vaccine}

Two attenuated strains of varicella are undergoing clinical trials for vaccination. ${ }^{53,99}$ The main advantage in using a vaccine would be to decrease the complications of varicella in children and adults, but it probably would have no action in those who are immunosuppressed. At best, vaccines prevent or ameliorate the development of zoster, but it would be virtually impossible to do a trial to decide this because of the numbers and time course involved. ${ }^{100}$

\section{Specific Treatment}

\section{Skin Treatment}

The main objective of treatment is rapid healing without the massive crust formation that so often gives rise to severe scarring.

Antivirals must be used only in the early vesicular stage of the disease when there is marked virus activity. Iodoxuridine, although insoluble in water, is highly soluble in dimethylsulphoxide; preparations are available in $5-40 \%$ solutions (Iduridin or Herpid). These can be applied as a paint by the patient or as presoaked dressings changed daily for the first 4 days by a nurse; they have been claimed to speed the onset of crusting, prevent secondary cropping 
and reduce acute and post-herpetic neuralgia. ${ }^{101-103}$ Many patients also prefer the fact that their rash is covered. Acyclovir 5\% ointment applied 3 times a day has also had similar claims of efficacy. ${ }^{104}$

Anti-inflammatory steroid creams and ointment should be applied when the vesicular phase has passed (usually 10 days after onset). We use a combination of cortisone and neomycin, applying it 3 times a day to the skin and lids; the antibiotic is useful for preventing secondary infection in the crusts. The greasy nature of the preparation prevents aggregation of crusts and aids their separation. Alternatives are Terra-Cortril spray (Pfizer) and Betnovate (Glaxo). Patients presenting late with large crusts, especially those erroneously treated with starch powder and calamine, should have them cleaned off with warm sterile saline washes followed by ointment. Subcuticular injections of steroids such as triamcinolone have been tried in the acute and late phases of the neuralgia with mixed results. ${ }^{105}$

Energetic massage of the affected skin area using a vehicle of lanolin or petroleum jelly can be most effective for neuralgia after crust separation and possibly also reduces scarring. It is based on the gate theory of sensory neural conduction: stimulation of the large afferent nerves with massage inhibits the smaller pain fibre transmissions. It is reputed to be best in the 'trigger' type of pain. More recently capsaicin has been reported as an effective vehicle, but the results are anecdotal ${ }^{106,107}$ and it is very irritant if it contacts the eye.

Topical management of post-herpetic neuralgia by the following must be considered when analgesics and massage fail: transcutaneous electrical nerve stimulation, short wave diathermy and ultrasound. ${ }^{108,109}$ Physiotherapy departments can provide these treatments, which may help some patients.

Pain clinics have an important part to play in refractory PHN. They can offer various treatments including subcutaneous injections of anaesthetics ${ }^{110}$ and steroids, and stellate ganglion block, which is probably most effective when given very early. ${ }^{111}$ They can also provide the supportive counselling which helps patients live with their pain. Neurosurgery is not recommended because it is often unsuccessful and may introduce other problems such as neurotrophic ulcer formation.

\section{Lid Treatment}

The same topical agents as described for the skin may be used for the lids. If there is severe scarring of the lids it may be necessary to epilate and electrolyse the trichiasis or to correct lid deformities by plastic surgery. Chronic blepharitis should be treated by lid toilet and the application of antibiotic ointment to the lid margins twice a day.

\section{Ocular Therapy}

The objectives of ocular therapy are to minimise scarring, to reduce inflammation and to maintain a stable corneal epithelium and tear film.

\section{Antivirals}

Our experience with topical antivirals such as idoxuridine, adenine arabinoside and trifluorothymidine has been disappointing even though virus shedding occurs into the tear film and the corneal epithelium during acute keratoconjunctivitis. ${ }^{17}$ Despite early reports that acyclovir ointment controlled and prevented later ocular complications ${ }^{112}$ we have been unable to confirm this. ${ }^{113,114}$ In a recent doublemasked trial we found that acyclovir alone was inferior to steroid for controlling inflammation but when combined with steroid led to less rebound inflammation on withdrawal of treatment. Moreover we found that the early conjunctivitis and microdendritic keratitis reported to respond so well to acyclovir are self-limiting, and placebo drops seem to show the same result. Furthermore in cases of chronic neurotrophic keratitis most antivirals will further compromise the already unstable corneal epithelium.

\section{Antibiotics}

Antibiotic drops such as chloramphenicol may be used to prevent secondary infection during the acute stage when lid vesicles are discharging and forming crusts or a mucopurulent conjunctivitis is present. Tetracycline ointment is very effective for keratoconjunctivitis when applied twice daily to chronically scarred or inflamed lid margins, since they become a focus for staphylococcal secondary infections.

\section{Anti-inflammatory Agents}

As scarring of the eye in zoster is the result of inflammation, the mainstay of therapy for the ocular complications of herpes zoster is corticosteroid, which is essential for scleritis, sclerokeratitis, disciform and mucous plaque keratitis, diffuse corneal oedema, significant iritis and hypertensive iritis. At the first evidence of these complications $0.1 \%$ dexamethasone drops should be instilled every 4 hours. Prompt treatment at the start of inflammation cuts down the ischaemic and fibrotic scarring that usually develops. Once control is achieved, the potency and frequency of administration can be reduced and the dose of topical steroids titrated against the degree of disease activity in the eye. ${ }^{81}$ This is a slow, cautious process and may extend over a period of years. The main problem is the tendency of the inflammation to relapse, particularly with too rapid or abrupt a withdrawal. As well as reducing the frequency of administration of the drug, serial logarithmic dilutions or a change, to another weaker steroid may be made (e.g. from dexamethasone to betamethasone to prednisolone). Many of the more intelligent patients can titrate their own dose, which may be reduced to as little as $0.03 \%$ prednisolone daily to maintain control. ${ }^{81}$

Precautions with topical steroids. The important obligations of steroid management are careful follow-up and examination to detect toxic side effects. Patients on topical steroids may develop glaucoma, cataract, secondary infections, mydriasis and ptosis. They also tend to develop a dependency on them so that withdrawal may be difficult without causing a recurrence of ocular inflammation. ${ }^{43}$ Clearly, if glaucoma is detected, the dose of steroid must 
be reduced and, if persistent, clobetasone or fluorometholone drops must be used. However, in some patients it may be difficult to differentiate a steroid glaucoma from hypertensive iritis, particularly in mucous plaque keratitis, and a helpful technique is to increase the dose of steroid and review in 2 days. If the pressure decreases the steroid dose must be maintained at a higher level; if not it must be reduced and antiglaucoma treatment such as timolol started. When this fails it is advisable to use acetazolamide only in the short term while glaucoma surgery is prepared. Potent doses of steroid should be reduced as soon as possible to avoid inducing lens opacities, but in some cases it is impossible to know whether to attribute these to the chronic iritis. Mydriasis and ptosis can also be caused by zoster alone. Steroids must be used with great caution in patients with neurotrophic keratitis because of the risk of secondary infections. When using steroids regular slit lamp examination and applanation are essential.

\section{Artificial Tears, Wetting Agents and Mucolytics}

These are used for unstable corneal epithelium in an attempt to stabilise the surface and prevent mucus deposition. We have found it best to try the different artificial tears empirically to find the most satisfactory and to add Lacri-Lube ointment (Allergan). Acetylcysteine 10\% may be used to dissolve mucus deposits and prevent further deposition, particularly in mucous plaque keratitis. Lastly, it should not be forgotten that unfortunately long-term drop administration can lead to toxic changes to the epithelium from the preservatives in the drops. It is then essential to switch to preservative-free drops. Taping the eyelids closed with Blenderm is often useful for rapidly establishing a stable epithelium, but can be a trial if there is significant neuralgia.

\section{Surgery}

\section{Lids}

Lid margin deformities arising from scarring (e.g. ectropion and trichiasis) are best treated with corrective lid surgery. Full-thickness loss of the lid margin should be treated as a surgical emergency. A lateral half tarsorrhaphy should be carried out promptly in all cases of neurotrophic ulceration that have failed to respond to medical treatment, and may also be necessary in cases of chronic exposure and neuroparalytic keratitis. Many patients are averse to this procedure but must be persuaded that it provides rapid healing, security and dramatically reduces outpatient visits. Lastly, if the problem persists after a lateral tarsorrhaphy a middle third must be carried out.

\section{Intraocular Surgery}

Cataract extraction. The extracapsular technique with posterior chamber implant is surprisingly straightforward when undertaken in a quiescent phase. The main problem is post-operative inflammation, which may persist for more than a year but always seems to be controllable with a low dose of topical steroid.
Glaucoma surgery. Trabeculectomy is usually trouble free and post-operative inflammation is the only real problem. Later on there is a high incidence of cataract formation. ${ }^{44}$ We have little experience of laser trabeculoplasty in zoster but it may be a worthwhile short-term solution.

Combined cataract and glaucoma surgery. This may be necessary and we have found it most successful with the same proviso of covering post-operative inflammation.

Corneal surgery. Neglected disciform keratitis or sclerokeratitis frequently give rise to dense scarring and lipid deposits in the central cornea. These patients tend to do well with perforating corneal grafts, provided that the corneal sensation is preserved and there is not too much vascularisation or the vessels have been closed by argon laser treatment. ${ }^{45}$ Very rarely an urgent corneal graft has to be done in patients whose neurotrophic ulceration has perforated. The prognosis is not good as considerable difficulty may be encountered in establishing a stable corneal epithelium over the graft; because of this it is best to carry out a tarsorrhaphy at the same time. Keratectomy is sometimes necessary for band-shaped keratopathy and mucous plaques and our early experience of excimer laser ablation has been encouraging.

\section{Therapeutic Comment}

One of the most important aspects of the ocular complications in herpes zoster is their tendency to recur, even years after the rash. It should be remembered that some relapses may occur when the original attack of herpes zoster has either been forgotten or was so mild as to pass unnoticed. The stimulus for the relapse is often unknown, although the precipitate withdrawal of topical steroids is a potent cause (even if small doses are being used). Therefore follow-up must be long and thorough in those with ocular involvement and topical steroid must be slowly and cautiously withdrawn (over years if necessary).

\section{DISCUSSION}

What we hope we have presented here is an accurate and useful review of ophthalmic zoster over the last 20 years, before the advent of effective antivirals. The number of cases we have collected has made it possible to make some statistical deductions to support clinical impressions, and perhaps to clarify some of the folklore associated with a relatively uncommon and pleomorphic disease. Overall we feel we have a reasonably unbiased sample of the disease with perhaps a slight tendency for patients with mild ophthalmic zoster and no eye involvement not to present to us. Current treatment is effective in most areas, with notable exceptions: neuralgia, anaesthetic corneas, mucous plaque keratitis and chronicity. Whether acyclovir or newer antivirals will make a significant impact on these is perhaps too early to judge, but experience over the last 5 years suggests that the clinical problems have not altered much in either type or magnitude, except perhaps for the management of disseminated disease in the immunosuppressed.

There is still no satisfactory explanation for the patho- 
genesis of zoster, and without that, management will be restricted to minimising the damage which results, rather than preventing it. A large part of what we deal with clinically is a result of the immune response to the virus, and a therapeutic tightrope has to be negotiated when trying to modify this: too effective a suppression may enhance viral persistence and lead to a more chronic course with treatment dependence over many years. By the time zoster is apparent clinically, a lot of virus has already got into the tissues, and antivirals act only to restrict further proliferation: while this may help, all the disease manifestations are still likely to appear.

Herpes zoster seems likely to be with us until either the virus is eradicated or some means of preventing reactivation is found. For the moment, accurate clinical assessment and prompt treatment, where necessary, will help minimise this troublesome disease.

Key words: Iris atrophy, Latency, Megaplaque keratitis, Mucous plaque keratitis, Oculomotor palsies, Reactivation.

\section{REFERENCES}

1. Edgerton AE. Herpes zoster ophthalmicus. Arch Ophthalmol 1945;93:40-114.

2. Glyn C, Crockford, Gavaghan D, et al. Epidemiology of shingles. J R Soc Med 1990;83:617-9.

3. Worster-Drought C. Herpes zoster with localized muscular paralysis. BMJ 1923;1:970.

4. de Moragas JM, Kierland RR. The outcome of patients with herpes zoster ophthalmicus. Arch Dermatol 1957;75: 193-6.

5. Burgoon CF, Burgoon JS, Baldridge GD. The natural history of herpes zoster ophthalmicus. JAMA 1957;164: 265-9.

6. Slavin HB, Ferguson JJ. Zoster-like eruptions caused by the virus of herpes simplex. Am J Med 1950;8:456.

7. Walpita P, Darougar S, Marsh RJ, Cooper M. Development of an immunofluorescence test for the serodiagnosis of herpes zoster ophthalmicus. Br J Ophthalmol 1986;70:431-4.

8. Lightman S, Marsh RJ, Powell D. Herpes zoster ophthalmicus: a medical review. Br J Ophthalmol 1981;65: 539-41.

9. Stevens DA, Merigan TC. Interferon, antibody and other host factors in herpes zoster. J Clin Invest 1972;51:1170.

10. Marsh RJ. Herpes zoster ophthalmicus. Br J Hosp Med 1976;15:609-18.

11. Sandor EV, Millman A, Croxson TS, Mildvan D. Herpes zoster ophthalmicus in patients at risk for the acquired immune deficiency syndrome (AIDS). Am J Ophthalmol 1986;101:153-5.

12. Kestelyn P, Stevens AM, Bakkers E, et al. Severe herpes zoster ophthalmicus in young African adults: a marker for HTLV-III seropositivity. Br J Ophthalmol 1987;71:806-9.

13. Marsh RJ. Herpes zoster ophthalmicus and AIDS. Br J Ophthalmol 1987;71:805.

14. Guess HA, Broughton DD, Melton LJ, Kurland LT. Epidemiology of herpes zoster in children and adolescents: a population-based study. Paediatrics 1985;76:512-7.

15. Marsh RJ. Herpes zoster keratitis. Trans Ophthalmol Soc UK 1973;93:181-92.

16. Watson PG, Bovey E. Anterior segment fluorescein angiography in the diagnosis of scleral inflammation. Ophthalmology $1985 ; 1: 1-11$.

17. Piebenga LW, Laibson PR. Dendritic lesions in herpes zoster ophthalmicus. Arch Ophthalmol 1973;90:268-70.

18. Reijo A, Anti V, Jukka M. Endothelial cell loss in herpes zoster keratouveitis. Br J Ophthalmol 1983;67:751-4.
19. Sundmacher R, Miller O. The corneal endothelium in ophthalmic zoster. Klin Monatsbl Augenheilkd 1982;180: 271-4.

20. Adams GGW, Kirkness CM, Lee JP. Botulinum toxin A induced protective ptosis. Eye 1987;1:603-8.

21. Liesegang TJ. Corneal complications from herpes zoster ophthalmicus. Ophthalmology 1985;92:316-24.

22. Marsh RJ, Easty DL, Jones BR. Iritis and iris atropy in herpes zoster ophthalmicus. Am J Ophthalmol 1974;78: 255-60.

23. Klien BA, Farkas TG, Pseudomelanoma of the iris after herpes zoster ophthalmicus. Am J Ophthalmol 1964;57: 392.

24. Meller J. Zur Klinik und pathologischen Anatomie des Herpes Zoster Uveae. Z Augenheilkd 1920;43:450.

25. Lincoff HA, Wise GN, Romaine HH. Total detachment and reattachment of the retina in herpes zoster ophthalmicus. Am J Ophthalmol 1956;41:253-6.

26. Collier M. Two rare ocular manifestations of ophthalmic zoster: retinal periarteritis and dysoric nodules. Bull Soç Ophthalmol Fr 1959;59:737-41.

27. Yeo JH, Pepose JS, Stewart JA, et al. Acute retinal necrosis syndrome following herpes zoster dermatitis. Ophthalmology 1986;93:1418-22.

28. Lowder C, Margolis T, Logan A, et al. Herpes zoster multifocal chorioretinitis in AIDS patients. Invest Ophthalmol (Suppl) 1990;31:366.

29. Forster DJ, Pravin U, Frangieh GT, et al. Rapidly progressive outer retinal necrosis in the acquired immunodeficiency syndrome. Am J Ophthalmol 1990;110:341-8.

30. Ramsell TG. Complications of herpes zoster ophthalmicus. Am J Ophthalmol 1967;63:1796-8.

31. Marsh RJ, Dulley B, Kelly V. External ocular motor palsies in ophthalmic zoster. Br J Ophthalmol 1977;61:677-82.

32. Siegert P. Zoster exophthalmus und ophthalmoplegie. Klin Monatsbl Augenheilkd 1964;144:54-8.

33. Laws HW. Herpes zoster ophthalmicus complicated by contralateral hemiplegia. Arch Ophthalmol 1960;63: 273-80.

34. Acers TE. Herpes zoster ophthalmicus with contralateral hemiplegia. Arch Ophthalmol 1964;71:371-6.

35. Victor D, Green WR. Temporal artery biopsy in herpes zoster ophthalmicus with delayed arteritis. Am J Ophthalmol 1986;82:628-30.

36. Womack LW, Liesegang TJ. Complications of herpes zoster ophthalmicus. Arch Ophthalmol 1983;101:42-5.

37. Harding SP, Lipton JR, Wells JCD. Natural history of herpes zoster ophthalmicus: predictors of postherpetic neuralgia and ocular involvement. Br J Ophthalmol 1987;71: 353-8.

38. Scheie HG. Herpes zoster ophthalmicus. Trans Ophthalmol Soc UK 1970;90:899-937.

39. Marsh RJ. Corneal epithelial lesions in herpes zoster. In: The cornea in health and disease (VIIth Congress of the European Society of Ophthalmology). London: Academic Press/RSM, 1980:791-5.

40. Marsh RJ, Cooper M. Ophthalmic zoster: mucous plaque keratitis. Br J Ophthalmol 1987;71:725-8.

41. Mackie IA. Role of the corneal nerves in destructive disease of the cornea. Trans Ophthalmol Soc UK 1978;98: 343-7.

42. Marsh RJ, Fraunfelder FT, McGill JI. Herpetic corneal epithelial disease. Arch Ophthalmol 1976;94:1899-902.

43. McGill J, Chapman C. A comparison of topical acyclovir with steroids in the treatment of herpes zoster keratouveitis. Br J Ophthalmol 1983;67:746-50.

44. Marsh RJ, Cooper M. Ocular surgery in ophthalmic zoster. Eye 1989;3:313-7.

45. Marsh RJ. Argon laser treatment of lipid keratopathy. Br J Ophthalmol 1988;72:900-4. 
46. Portenoy RK, Duma C, Foley KM. Acute herpetic and postherpetic neuralgia: clinical review and current management. Ann Neurol 1986;20:651-64.

47. Garland J. Varicella following exposure to herpes zoster. N Engl J Med 1943;228:336-7.

48. Hope-Simpson RE. The nature of herpes zoster: a long term study and a new hypothesis. Proc R Soc Med 1965;58: 9-20.

49. Weller TH, Coons AH. Fluorescent antibody studies with agents of varicella and herpes zoster propagated in vitro. Proc Soc Exp Biol Med 1954;86:789.

50. Pavan-Langston D, McCulley JP. Herpes zoster dendritic keratitis. Arch Ophthalmol 1973;89:25-9.

51. Danson AJ, Scott JE. The complete DNA sequence of varicella-zoster virus. J Gen Virol 1986;67:1759-876.

52. Davison AJ, Wilkie NM. Location and orientation of homologous sequences in the genomes of five herpes viruses. $\mathrm{J}$ Gen Virol 1983;64:1927.

53. Weller TH. Varicella and herpes zoster. N Engl J Med 1982;309:1362-8, 1434-9.

54. Tullo A. HSV keratitis: latent and recurrent infection. In: Easty DL, Smolin G, editors. External eye diseases. London: Butterworth, 1985:133-53.

55. Cooper M. The epidemiology of herpes zoster. Eye 1987;1: 413-21.

56. Baba K, Yabuuchi H, Takahashi M, Ogra PL. Increased incidence of herpes zoster in normal children infected with VZV during infancy: community-based follow-up study. J Paediatr 1986;108:372-7.

57. Miller LH, Brunell P. Zoster: reinfection or activation of a latent virus? Observations on the antibody response. Am J Med 1970;49:480.

58. Cradock-Watson JE, Ridehalgh MKS, Bourne MS. Specific immunoglobulin responses after varicella and herpes zoster. J Hyg (Lond) 1979;82:319-36.

59. Ceretini R, Donati M, Rumpianesi F, Moroni A, Tosti A, Patrizi A, Varotti C, Negosanti M. Virological course of herpes zoster in otherwise normal hosts. J Med Microbiol 1983;16:303-8.

60. Weigle KA, Grose C. Molecular dissection of the humoral immune response to individual VZV proteins during chickenpox quiescence, reinfection and reactivation. J Infect Dis 1984;149:741-9.

61. Gershon AA, Steinberg SP. Inactivation of varicella-zoster virus in vitro: effect of leucocytes and specific antibody. Infect Immunol 1981;33:507-11.

62. Neumeyer DA, Hirsch MS. Inversion of T cell subsets before herpes zoster infection. N Engl Med J 1986;314: 1456.

63. Claoue CMP, Hodges TJ, Hill TJ, Blyth WA, Easty DL. The histology of the eye after zosteriform spread of herpes simplex virus in the mouse. Br J Exp Pathol 1987;68: 585-93.

64. Claoue CMP, Hodges TJ, Hill TJ, Blyth WA, Easty DL. Microbiological aspects and effect on the blink reflex. Eye 1988;2:318-23.

65. Blyth WA, Harbour DA, Hill TJ. Pathogenesis of zosteriform spread of herpes simplex virus in the mouse. J Gen Virol 1984;65:1477-86.

66. Simmons A, Nash AA. Zosteriform spread of herpes simplex virus as a model of recrudescence and its use to investigate the role of immune cells in prevention of recurrent disease. J Virol 1984;52:816-21.

67. Hyman RW, Ecker JR, Tenser RB. Varicella-zoster virus RNA in human trigeminal ganglia. Lancet 1983;2:814-6.

68. Pichini B, Ecker JR, Grose C, Wyman RW. DNA mapping of paired VZV isolates from patients with shingles. Lancet 1983;2:1223-5.

69. Straus ES, Reinhold W, Smith HA, Rutechan WT, Henderson DK, Blaese RM, Hay J. Endonuclease analysis of viral DNA from varicella and subsequent zoster infections in the same patient. N Eng J Med 1984;311:1362-4.

70. Claoue CMP, Hodges TJ, Darville JM, Hill TJ, Blyth WA, Easty DL. Possible latent infection with herpes simplex virus in the mouse eye. J Gen Virol 1990;71:2385-90.

71. Juel-Jensen BE, MacCullum FO. Herpes simplex, varicella and zoster. London: Heinemann, 1972:99-163.

72. Rummelt V, Wenkel H, Fleckenstein B, Nauman GOH. Varicella zoster virus DNA: in situ hybridisation in eyes and corneal buttons obtained following herpes zoster ophthalmicus. University of Erlangen-Nurnberg, Germany, International Conference on Herpetic Eye Diseases.

73. Head H, Campbell AW. The pathology of herpes zoster and its bearing on sensory localisation. Brain 1900;23: 353-523.

74. Esiri MM, Tomlinson AH. Herpes zoster: demonstration of virus in the trigeminal nerve and ganglion by immunofluorescence and electron microscopy. J Neurol Sci 1972;15: 35-48.

75. Rejke-Nielsen E, Oster S, Pedersen B. Herpes zoster ophthalmicus and the mesencephalic nucleus. Acta Pathol Microbiol Immunol Scand 1986;94:263-9.

76. Oxman MN. Varicella and herpes zoster. In: Fitzpatrick TB, Freeberg M, editors. Dermatology in general medicine. New York: McGraw-Hill, 1987: chapter 160.

77. Jemsek J, Greenberg SB, Tabar L, et al. Herpes zosterassociated encephalitis: clinicopathologic report of 12 cases and review of the literature. Medicine 1983;62: 81-97.

78. Naumann G, Gass JDM, Font RL. Histopathology of herpes zoster ophthalmicus. Am J Ophthalmol 1968;65: 533.

79. Redslob E. Troubles pupillaires dans le zona ophtalmique. Rev Oto-Neuro-Ophtalmol 1923;1:509.

80. Bonnet P. La topographie en secteur des lesions de la cornée dans le zone ophtalmique. Bull Soc Ophtalmol Fr 1939;51:434.

81. Marsh RJ. Current management of ophthalmic herpes zoster. Trans Ophthalmol Soc UK 1976;96:334-7.

82. Elliott FA. Treatment of herpes zoster with high doses of prednisolone. Lancet 1964;2:610-1.

83. Eaglstein WH, Katz R, Brown JA. The effects of early corticosteroid therapy on the skin eruption and pain of herpes zoster. J Am Med [A] 1970;211:1681-3.

84. Rado JP, Tako J, Geder L, Jeney E. Herpes zoster: house epidemic in steroid-treated patients. Arch Intern Med 1965; $116: 329$.

85. Merselis JG, Kaye D, Hook EW. Disseminated herpes zoster. Arch Intern Med 1964;113:679-86.

86. Marsh RJ. Current management of ophthalmic zoster. Aus NZ J Ophthalmol 1990;18:273-9.

87. Stevens DA, Jordan GW, Weddell TF, Merrigan TC. Adverse effect of cytosine arabinoside on disseminated zoster in a controlled trial. N Engl J Med 1973;289:873-8.

88. Marsh RJ, Laird R, Atkinson A, et al. A controlled trial of intravenous therapy with adenine arabinoside (AraA) in ophthalmic zoster. In: Sondemacher R, editor. Herpetic eye diseases. Munich: Bergman Verlag, 1981: 449-54.

89. Galbraith AW. Treatment of acute herpes zoster with amantadine hydrochloride (Symmetrel). BMJ 1973;4:693-5.

90. Balfour HH Jr, Bean B, Laskin OL, et al. Acyclovir halts progression of herpes zoster in immunocompromised patients. N Engl J Med 1963;308:1448-53.

91. Peterslund NA, Ipsen J, Schonheyder H, et al. Acyclovir in herpes zoster. Lancet 1981;2:827-30.

92. Bean B, Brain C, Balfour H. Acyclovir therapy for acute herpes zoster. Lancet 1982;2:118-21.

93. McGill J, MacDonald DR, Fall C, et al. Intravenous acyclovir in acute herpes zoster infection. J Infect 1983;6: 157-61. 
94. McKendrick MW, McGill JL, Bell AM, et al. Oral acyclovir for herpes zoster. Lancet 1984;2:925.

95. McKendrick MW, McGill JI, Wood MJ. Lack of effect of acyclovir on postherpetic neuralgia. BMJ 1989;298:431.

96. Cobo IM, Foulks GN, Liesgang T, et al. Oral acyclovir in the therapy of acute herpes zoster ophthalmicus: an interim report. Ophthalmology 1985;92:1574-83.

97. Cobo IM, Foulks GN, Liesgang T, et al. Oral acyclovir in the treatment of acute herpes zoster ophthalmicus. Ophthalmology 1986;93:763-70.

98. Watson CPN, Evan RJ, Reed K, et al. Amitryptyline versus placebo in postherpetic neuralgia. Neurology 1982;32: 671-3.

99. Weibel RE, Neff BJ, Kuter BJ, et al. Live attenuated varicella virus vaccine. N Engl J Med 1984;310:1409-15.

100. Plotkin SA, Arbetter AA, Starr SE. The future of varicella vaccine. Postgrad Med J 1985;61(Suppl 4):155-62.

101. Dawber R. Idoxuridine in herpes zoster: further evaluation of intermittent topical therapy. BMJ 1974;2:526-7.

102. Juel-Jenson BE, MacCallum FO. Herpes simplex, varicella, and Zoster. London: Heinemann, 1972:163.

103. Marsh RJ. Idoxuridine (IDU) in dimethyl sulfoxide (DMSO) in the treatment of ophthalmic zoster. Ophthalmol Digest 1977;39:17-9.

104. Levin MJ, Zaia JA, Hershey BJ, et al. Topical acyclovir treatment of herpes zoster in immunocompromised patients. J Am Acad Dermatol 1985;13:590-6.
105. Miller RD, Munger WL, Powell BE. Chronic pain and local anaesthetic blockade. In Cousins MJ, Bridenbough PO, editors. Neural blockade in clinical anaesthesia and management of pain. Philadelphia: Lippincott, 1980.

106. Bernstein JE, Bickers DR, Dahl MV, et al. Treatment of chronic postherpetic neuralgia with topical capsaicin. J Am Acad Dermatol 1987; 17:93-6.

107. Bucci FA, Gabriels CF, Krohel GB. Successful treatment of postherpetic neuralgia with capsaicin. Am J Ophthalmol 1988;106:758-9.

108. Loeser JD, Black RG, Christman A. Relief of pain by transcutaneous electrical stimulation. J Neurosurg 1975;42: 308-14.

109. Long DM. External electrical stimulation as a treatment of chronic pain. Minn Med 1973;57:195-8.

110. Riopelle JM, Noaghi M, Grush KP. Chronic neuralgia incidence following local anaesthesia therapy for herpes zoster. Arch Dermatol 1984;120:747-50.

111. Colding A. The effect of sympathetic blocks on herpes zoster. Acta Anaesthiol Scand 1964;13:133-41.

112. McGill J. Topical acyclovir in herpes zoster ocular involvement. Br J Ophthalmol 1981;65:542-5.

113. Marsh RJ, Cooper M. Acyclovir and steroids in herpes zoster kerato-uveitis. Br J Ophthalmol 1984;68:904.

114. Marsh RJ, Cooper M. Double-masked trial of topical acyclovir and steroids in the treatment of herpes zoster ocular inflammation. Br J Ophthalmol 1991;75:542-6. 